\title{
Mechanics-based fragility curves for Italian residential URM buildings
}

\author{
Marco Donà ${ }^{1,2}$ D Pietro Carpanese ${ }^{2} \cdot$ Veronica Follador $^{2} \cdot$ Luca Sbrogiò $^{3}$. \\ Francesca da Porto ${ }^{2}$
}

Received: 29 January 2020 / Accepted: 6 August 2020 / Published online: 8 September 2020

(c) The Author(s) 2020

\begin{abstract}
Seismic risk assessment at the territorial level is now widely recognised as essential for countries with intense seismic activity, such as Italy. Academia is called to give its contribution in order to synergically deepen the knowledge about the various components of this risk, starting from the complex evaluation of vulnerability of the built heritage. In line with this, a mechanics-based seismic fragility model for Italian residential masonry buildings was developed and presented in this paper. This model is based on the classification of the building stock in macro-typologies, defined by age of construction and number of storeys, which being information available at national level, allow simulating damage scenarios and carrying out risk analyses on a territorial scale. The model is developed on the fragility of over 500 buildings, sampled according to national representativeness criteria and analysed through the Vulnus_4.0 software. The calculated fragility functions were extended on the basis of a reference model available in the literature, which provides generic fragilities for the EMS98 vulnerability classes, thus obtaining a fragility model defined on the five EMS98 damage states. Lastly, to assess the reliability of the proposed model, this was used to simulate damage scenarios due to the 2009 L'Aquila earthquake. Overall, the comparison between model results and observed damage showed a good fit, proving the model effectiveness.
\end{abstract}

Keywords Residential masonry buildings $\cdot$ Macro-typologies $\cdot$ Territorial-scale seismic vulnerability $\cdot$ Fragility model $\cdot$ Seismic damage scenarios $\cdot$ Seismic risk management

\section{Introduction}

Italy is historically one of the European countries with the highest seismic activity and related number of victims, around 160,000 in the last two centuries (with 85,000 victims in the 1908 Messina earthquake of magnitude $M_{w} 7.1$ ). In the twentieth century, earthquakes with a value of $M_{w} \geq 6.5$ were at least seven and, only in the last 10 years, four events have reached or exceeded a magnitude of 6.0 (Italian Civil Protection Department—DPC 2018).

Marco Donà

marco.dona.1@unipd.it

Extended author information available on the last page of the article 
Over the last 50 years, earthquakes forced the Italian state to sustain emergency management, recovery and reconstruction costs amounting to around 180 billion euros, of which 130 billion for earthquakes from 1968 to 2003 (discounted to 2003) and 45 billion (most likely estimate) for the recent events of L'Aquila 2009, Emilia 2012 and Central Italy 2016 (DPC 2018; further information can be found in Swiss Reinsurance Company 2019). Therefore, without considering casualties, impairment of historical and artistic heritage (difficult to quantify), loss in tourist trade (Mazzocchi and Montini 2001) and the high indirect consequences on the production sector (Donà et al. 2019; Braga et al. 2014), the cost of Italian earthquakes is around 3.6 billion euros per year.

Although the issue of victims remains of primary importance, it is clear that these economic figures are hardly sustainable for a country. Considering the high ratio between seismic costs and released earthquake energy, it is also clear that Italy is a poorly resilient country. The main reason for this is basically the high vulnerability of the built heritage connected with the low insurance penetration of the country, where the government assumes the role of insurer of last resort, making this situation unsustainable.

Since 2017, the Italian government has introduced important incentives to involve the private sector as much as possible in building the country's resilience against natural disasters. In particular, tax deductions were introduced for individuals and companies (Law 232/2016 and Italian Ministry of Infrastructures DM 58/2017- “Sismabonus"), in order to recover up to $85 \%$ (with an upper bound) of the cost of seismic retrofit interventions on productive and residential buildings in highly to moderately seismic areas. Subsequently, incentives were also introduced (Law 205/2017) for the purchase of insurance policies against natural disasters for residential buildings. In addition, during recent years, plans to explain seismic risk to a wider public and to raise awareness among citizens have spread across the country and have developed into well-established initiatives, such as the dissemination campaign "I don't take risks", organised by the DPC, the National Institute of Geophysics and Volcanology (INGV), the Italian Laboratories University Network of Seismic Engineering (ReLUIS) and the National Association of the Public Aids (ANPAS).

All this is in line with the "Sendai Framework for Disaster Risk Reduction 2015-2030" (United Nations 2015), adopted in March 2015 at the Third World Conference of the United Nations in Sendai (Japan), which provides indications on the actions to be implemented for the priority areas: "Priority 3: investing in disaster risk reduction for resilience. Priority 4: enhancing disaster preparedness for effective response ...". Responding also to "Priority 1: understanding disaster risk" and "Priority 2: strengthening disaster risk governance to manage disaster risk" of the Sendai Framework, which called for an updating of risk assessments by various countries, the Italian Civil Protection Department recently released the "National Risk Assessment" (DPC 2018), a document that provides an updated overview of potential major disasters in Italy, and that also contains the results of this study as a contribution to the seismic vulnerability assessment of the residential building heritage in Italy.

Techniques for assessing the seismic vulnerability of entire building stocks generally aim to define logonormal fragility curves, which correlate seismic intensity parameters (e.g. the Peak Ground Acceleration, PGA) with the probabilities of exceeding some damage states (DSs) of buildings. Many methods are found in the literature (Calvi et al. 2006), which are based on three main approaches: empirical, which calibrates fragility curves based on damage information surveyed in the aftermath of the event (among the others, Rossetto et al. 2013; Rota et al. 2008; Lagomarsino et al. 2015; Rosti et al. 2018; Cescatti et al. 2019); analytical (or mechanics-based), which defines fragility based on structural models and analyses to simulate the seismic behaviour of buildings (Cosenza 
et al. 2005; D’Ayala et al. 2014; Lagomarsino and Cattari 2014; Tecchio et al. 2016; Del Gaudio et al. 2018; Masi et al. 2019); hybrid, which uses information from both empirical and analytical methods (Kappos et al. 2006).

In general, there is no method that is better than the others, as they all have pros and cons. For example, an empirical fragility model is calibrated on specific areas affected by the earthquake (therefore on specific building types and situations) and includes a series of uncertainties on surveys and measurements of seismic damage and ground shaking intensity that are responsible for increasing the dispersion of fragility curves. On the other hand, a mechanics-based fragility model requires the retrieval of a significant amount of geometric and design information, through time-consuming surveys and cognitive studies; moreover, its reliability is strongly related to that of the structural models and analyses and to the quantity and quality of the information collected. However, analytical methods can increasingly rely on innovative sensing technologies (e.g., aerophotogrammetry, Google Maps, drones, remote sensing etc.), allowing the collection of numerous data remotely with considerable time savings (Vona et al. 2017; Fabris et al. 2013), and on innovative methods of statistical inference, allowing to derive all the parameters necessary to define the structural models on the basis of a few main measured characteristics (Campostrini et al. 2017; Taffarel et al. 2018).

In this context, the present work aimed to derive a novel mechanics-based fragility model for territorial-scale vulnerability assessment of the Italian residential masonry buildings. To this end, the residential URM heritage was divided into ten macro-typologies, defined by age of construction and number of storeys, which are information gathered at national level by means of census and made available by the Italian National Institute of Statistics (ISTAT).

This model is calibrated on the fragility of over 500 buildings, sampled on the basis of representativeness criteria at national level and from a large database of information on historic buildings, which has been collected over the years by our research group with traditional survey methods. The available information was systematised and integrated with that obtained from design documents, technical manuals and design regulations of the various construction periods, in order to obtain a quantitatively sufficient and homogeneous information for all building macro-typologies. The sampled buildings were analysed through the Vulnus_4.0 software (Valluzzi et al. 2009), defining a first model (Vulnus model) that returns the fragility of all macro-typologies for a moderate-severe DS, i.e. DS2-3 according to the EMS98 damage scale (Grünthal 1998). To describe fragility for multiple DSs, the Vulnus model was extended using a reference model available in the literature, which provides the fragility for all vulnerability classes (not related to specific building types) and DSs defined in EMS98. Overall, the model obtained is hybrid, calibrated on mechanics and derived with a heuristic approach which, extending the approach presented in Valluzzi et al. (2009), represents another element of novelty. For validation purposes, this model was used to simulate damage scenarios due to the 2009 L'Aquila earthquake and the results were compared with the observed damage. The results confirmed the model effectiveness, showing encouraging similarities between simulated and surveyed damage for all analysed DSs, despite the many uncertainties that characterize the study.

The ultimate goal is to provide the Civil Protection Department with a suitable tool for simulating seismic scenarios-useful for supporting the emergency phase through real-time loss estimates-and for territorial-scale risk assessments-necessary to plan mitigation strategies in the perspective of sustainability and prioritization in the use of resources. 


\section{Method of derivation of fragility curves}

The research group of the University of Padova has been active for years on the themes of seismic vulnerability assessment of the built heritage, with special focus on vulnerability and fragility assessment of URM buildings in historic centres (Bernardini 2000; Munari 2009), comparison of methods for vulnerability assessment (Valluzzi et al. 2007), analysis and interventions on clustered buildings (da Porto et al. 2013), development of methods based on bayesian inference for territorial analysis (Taffarel 2016), emergency management and structural interventions (Modena et al. 2010), among the others. One of the outcomes of this research activity has been the development of a calculation tool, called Vulnus (Bernardini et al. 1990, 2008), initially used for the seismic safety checks of URM buildings by means of automated linear kinematic analyses, subsequently evolved into a seismic vulnerability assessment tool, introducing also the Fuzzy set theory (Bernardini and Tonon 2004), and then updated to the latest version Vulnus_4.0 (Valluzzi et al. 2009).

For load-bearing URM buildings, Vulnus_4.0 processes information on building geometry (in plan and elevation), material properties, types of resistant system, floors and roof and their features (e.g., lightweight or heavy decks, balanced or un-balanced roofs), lack or presence of wall-to-wall connections and their effectiveness and also other qualitative information. Based on this information, Vulnus_4.0 first calculates the horizontal accelerations (a) that activate the main in-plane (IP) and out-of-plane (OOP) mechanisms, respectively through resistance checks and linear kinematic analyses; then, on the basis of these values, it derives the IP and OOP critical triggering accelerations that, normalized to gravity acceleration $g(\mathrm{a} / \mathrm{g})$, define the resistance indexes $I_{1}$ and $I_{2}$ respectively.

Specifically, $I_{1}$ represents the shear resistance of the building in its weak direction, normalized to its total weight and is obtained by assessing the total shear resistances offered by parallel wall systems, analysed as rigidly coupled by the deck and in their average plane. In the case of irregular buildings, the effects of the uneven distribution of stresses on the shear strength are taken into account by applying appropriate corrective factors to $I_{1}$ (Valluzzi et al. 2009).

$I_{2}$ is a more complex parameter, depending on the possible out-of-plane mechanisms associated with the vertical and horizontal masonry portions of each wall (taken one meter wide). The mechanisms assessed for vertical strips, whose triggering accelerations define $I_{2}{ }^{\prime}$, are: tilting of the overall walls and tilting and flexural collapse of the walls at the top storey. Those for the horizontal strips, who define $I_{2}{ }^{\prime \prime}$, are: bending and arching mechanism failure at the top storey, tilting and flexural collapse of the arch shoulders at the top storey and detachment of the transverse walls still at the top. For each wall, Vulnus_4.0 calculates the sum of $I_{2}{ }^{\prime}$ and $I_{2}{ }^{\prime \prime}$, and the minimum value defines $I_{2}$ (Valluzzi et al. 2009).

Subsequently, Vulnus_4.0 computes and returns another index, $I_{3}$, which takes into account other relevant vulnerability information, although qualitative, relating to the types of resistant system, floors, roof and foundations, the configuration and regularity in elevation of the building, the state of preservation, the presence of structural interventions and, furthermore, the quality of the information. Specifically, $I_{3}$ is based on the vulnerability parameters identified by the "Second Level" form of G.N.D.T. (Ferrini et al. 2003) and is calculated as a weighted average of the scores assigned to these parameters with expert judgment (Valluzzi et al. 2009). $I_{3}$ ranges from 0 to 1 , with 0 indicating a building design according to anti-seismic criteria.

Based on the $I_{1}, I_{2}$ and $I_{3}$ indices and the Fuzzy set theory, Vulnus_4.0 finally provides estimates of expected seismic damage, in the form of fragility curves for incremental 
values of Peak Ground Acceleration (PGA). The Fuzzy theory is used to converts $I_{1}, I_{2}$ and $I_{3}$ into fuzzy subsets, thus allowing to statistically evaluate the influence of parameters that cannot be quantified exactly (such as those summarised by $I_{3}$ ), and the uncertainties on the quantifiable parameters not carefully measured (i.e., associated with a poor information quality) or characterized by high variability (such as the material properties). Further information can be found in Valluzzi et al. (2009) and Munari (2009).

In particular, Vulnus_4.0 computes three cumulative probability distributions (fragility curves) associated with the triggering of IP and/or OOP mechanisms. One of these curves, referred to as White, represents the average building vulnerability, whereas the other two, referred to as Lower- and Upper-Bound, define a range of vulnerability due to the various sources of uncertainty and therefore to the quality of information.

These fragility curves, based on expert judgment and observations of seismic damage, were associated with an intermediate DS between the "moderate" and "severe" ones of the EMS98 scale, which defines the following DSs: slight damage DS1, moderate damage DS2, severe damage DS3, partial collapse DS4 and complete collapse DS5 (Munari 2009). An equivalence of Vulnus fragility curves with damage DS2-3 is a reasonable assumption considering that the triggering acceleration of a certain mechanism, assessed by linear analysis, is a necessary condition for the mechanism activation (DS2), can be very close to the maximum system capacity (DS3), especially for IP mechanisms, but it is not yet a sufficient condition to turn the mechanism into a partial collapse (DS4).

\section{Macro-typologies and sampling of Italian URM buildings}

\subsection{Definition of building macro-typologies and representativeness criteria}

As already mentioned, territorial-level vulnerability assessments carried out on a mechanical basis require a substantial effort to collect the numerous data necessary for calibrating the various structural models and methods of analysis. Therefore, in light of the relatively low number of buildings that can be reasonably analysed, in order to obtain vulnerability results as representative as possible, it is first necessary to define appropriate building macro-typologies and subsequently perform a representative sampling of the built heritage for each typological class, with the ultimate goal of deriving typological fragility curves representing the average vulnerability of the various classes.

The criteria for defining macro-typologies should obviously be based on those factors that most influence the vulnerability; however, the parameters required to define these criteria should decrease as much as the extent of the analysis increases at a territorial level. On the contrary, the limits in acquiring knowledge of so much information on a large territorial scale would impair the possibility of effectively using the developed typological fragility curves for the sought vulnerability assessment purposes.

To date, the main information on the building stock available for rapid vulnerability estimates, collected by ISTAT throughout the national territory during census, and returned up to the level of the single municipality, regards the type of material (reinforced concrete, masonry and "other"), the age of construction and the number of storeys. Although such information may seem limited, careful use allows to rationally address the problem of seismic vulnerability estimates on a national scale, albeit in a simplified way.

Indeed, the main geometric factors (such as arrangement of resistant systems, presence of structural irregularities and contiguous buildings), typological-constructive factors (i.e., 
types of lateral resistant systems, foundations, floors and roofs), as well as the main material properties (weight and resistance) and construction details, are strongly correlated with the construction age, although they may show some variability. Clearly, this is due to the evolution of scientific and technological knowledge, manufacturing and construction techniques, materials, as well as the drafting and updating of construction standards. In addition, the number of storeys in the building is another significant information, as it is associated with the dynamic behaviour and seismic demand of the building.

Therefore, based on the main information provided by ISTAT and expert judgment, a macro-typology classification was proposed (Table 1) for URM buildings of the Italian built heritage, based on construction age and building height. In particular, the adopted ranges of construction ages are a compromise between the years in which a new census, with updated data, was carried out (i.e., 1919, 1945, 1961, 1971, 1981, 1991, 2001, 2011), and the periods in which important changes in construction methods, due to technological developments and the delivery of construction standards, can be identified. This is a simplified classification, consistent with the relevant significant uncertainties; however, the resulting ages are coherent with those defined in AeDES form (Baggio et al. 2007).

As regards the sampling of buildings for the various macro-typologies, i.e. the case studies to derive the typological fragility curves, the following criteria were considered.

- Representativeness with respect to the variability of the building heritage with the geographical position. Indeed, in the same historical period, and especially for the most ancient and less industrialised ones, a great variety of construction techniques can be found in Italy, depending on the geographical areas (not necessarily corresponding to administrative boundaries). Differences and peculiarities are noticeable up to the municipal level; the reasons are historical, related to the complex morphology and climatic variability of the country, the presence of local building materials and other reasons of opportunity. The knowledge of this rich building diversity and of its significance on a territorial scale is essential for its appropriate inclusion in vulnerability assessment.

- Representativeness with respect to the typological variability of the buildings, in terms of number of storeys and global dimension (single houses, terraced houses, small or medium-sized apartment buildings, etc.), for each construction age.

The first criterion, i.e. the geographical representativeness, was taken into account through a nationwide diffused sampling, carefully selecting representative buildings belonging to 65 municipalities and nine regions, located in Southern, Central and Northern Italy. As can be seen from Table 1, 525 buildings were sampled overall, with 80 case studies for each construction age, except for the Pre-1919 period, where the buildings are over 200. In this period, indeed, the local variability of construction practices was

Table 1 Macro-typologies of Italian residential URM buildings and number of sampled buildings

\begin{tabular}{llllll}
\hline Construction age & Pre-1919 & $1919-1945$ & $1946-1960$ & $1961-1980$ & Post-1980 \\
No. storeys $(n)$ & $\leq 2$ & $\leq 2$ & $\leq 2$ & $\leq 2$ & $\leq 2$ \\
& $\geq 3$ & $\geq 3$ & $\geq 3$ & $\geq 3$ & $\geq 3$ \\
\hline No. sampled buildings & 205 & 80 & 80 & 80 & 80 \\
\hline
\end{tabular}


definitely higher than in later periods, due to the absence of any industrialised construction process, material and method, and to the absence of relevant construction manuals or standards, which started spreading in Italy during the first decades of the XX Century. In addition, according to ISTAT, Pre-1919 macro-typology holds the largest share of residential masonry buildings, which corresponds to $30 \%$ of the total.

Future studies on the geographical characterization of the Italian residential heritage will surely be useful both to improve the representativeness of the current sample and to define further typological classes of buildings based on their location, for more precise vulnerability estimates. This type of studies, which relies on the survey of the main typological-constructive characteristics of the built heritage at the municipal level, are currently underway through the CARTIS project by some research groups of Italian universities, in coordination with the DPC and ReLUIS (Cacace et al. 2018).

As regards the second criterion, i.e. the typological representativeness, the sampling was aimed at satisfying as much as possible the statistical distributions of buildings obtained by processing ISTAT data: distribution by number of storeys, within the same macro-typology; distribution by number of housing units, within buildings having the same number of storeys. In the second case, ISTAT database did not allow to process the information on construction ages and material types together; therefore, this distribution represents the variability of the total built heritage. Nevertheless, in the absence of other information, it was assumed to be enough representative to calibrate our database.

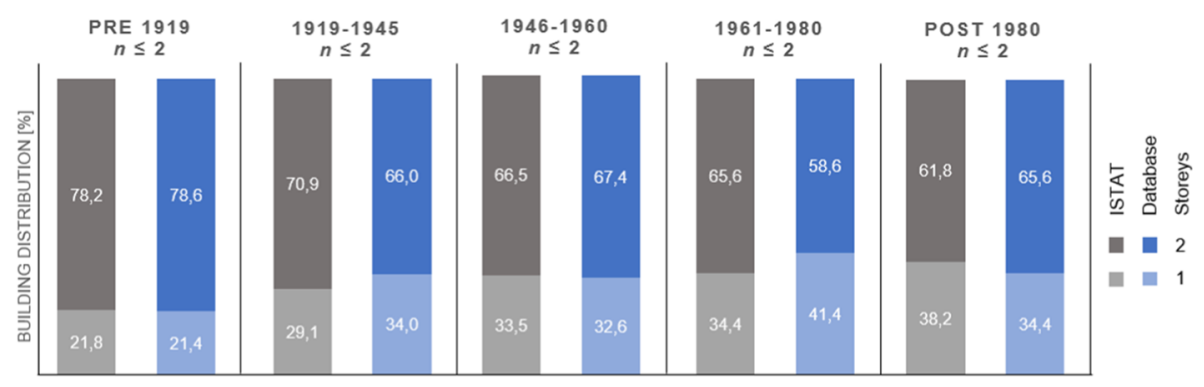

(a)

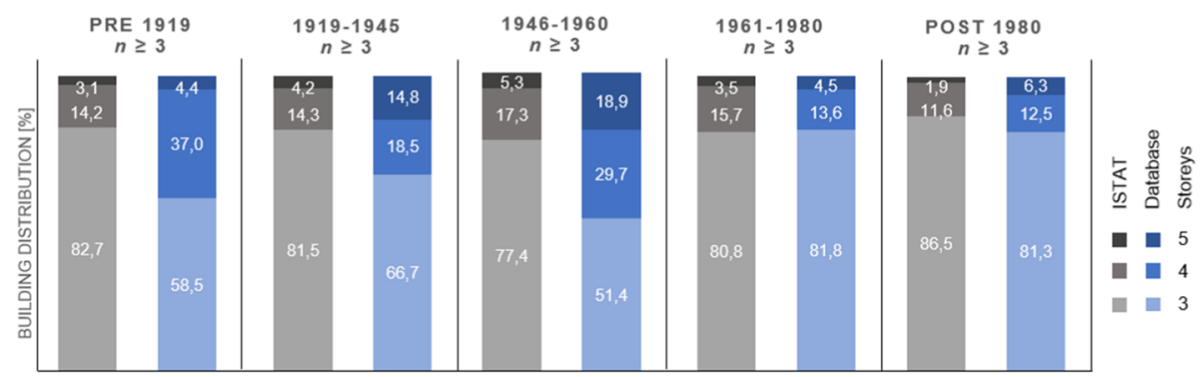

(b)

Fig. 1 Distribution of buildings by number of storeys $(n)$, within each macro-typology, according to ISTAT data and the database of sampled buildings. a $n \leq 2 ; \mathbf{b} n \geq 3$ 


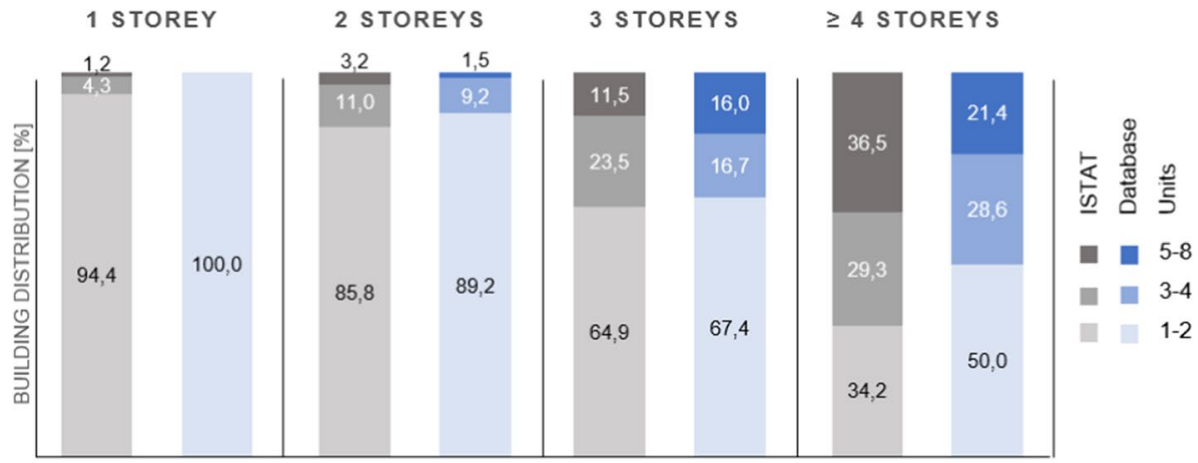

Fig. 2 Distribution of buildings by number of housing units, per number of storeys, according to ISTAT data and the database of sampled buildings

Figures 1 and 2 show the comparison between these ISTAT statistical distributions and the database of sampled buildings.

\subsection{Sampling of buildings assumed as case studies}

It is understandable that a detailed sampling of geometric, constructive and material information for over 500 buildings (to calibrate the various models in Vulnus_4.0) would be too expensive, for the purpose of this project, if exclusively based on direct surveys. So, to create the database of case studies, various sources of information were used and integrated in order to obtain information as complete as possible in a sustainable and cost-effective way. One of the main sources of building case-studies, which contributed about $50 \%$ of the database, was constituted by surveys directly carried out by the research group of the University of Padova in recent years, in the aftermath of the various seismic events, or for preliminary assessment of buildings and centres, or for other research purposes. The available data were reworked and integrated for this study. The integration of various information sources made it possible to obtain more robust global information, in relation to the many uncertainties implied in this study and to the possibility of using only the very specific data collected on certain case studies.

In particular, for the various construction periods, the main technical architecture manuals (e.g. Cantalupi 1862; Curioni 1868; Donghi 1905; Arosio 1941; Ormea 1951; Carbonara 1954; Guenzi 1981; Di Sivo 1981) and Italian construction standards (e.g., Italian Royal Decree RD 193/1909; RD 2089/1924; RD 640/1935, Law 1684/1962; Italian Ministry of Infrastructures DM 1986, 1987, 1996) were examined in order to identify the most recurring typological-constructive characteristics, as well as the typical properties of building materials for each period. In addition, useful information was obtained from the results of the TABULA project (Corrado et al. 2014), which summarizes at national level the main material and constructive information by age and type of building (i.e., single houses, multi-family houses, terraced houses and apartment buildings) and from the "Circolare no. 617” (Italian Ministry of Infrastructures 2009), which provides (in Table C8A.2.1) indications about material properties.

This was essential to create the rational basis for performing the most representative sampling possible (relying on representative documents and expert judgments) and to integrate the missing information for the various case studies, through the reference 
Table 2 Summary of reference information for each construction age

\begin{tabular}{|c|c|c|c|c|}
\hline & Pre-1919 & & $1919-1945$ & \\
\hline Material & Stones & Solid bricks & Solid bricks & Solid bricks \\
\hline Compressive strength (MPa) & 2.6 & 4.0 & 4.0 & 4.0 \\
\hline Tensile strength (MPa) & 0.085 & 0.14 & 0.14 & 0.14 \\
\hline Specific density $\left(\mathrm{kg} / \mathrm{m}^{3}\right)$ & 2100 & 1800 & 1800 & 1800 \\
\hline Floor type & Wood & Wood & Wood precast RC & Hourdis hollow-tile \\
\hline Friction coefficient (-) & 0.3 & 0.3 & 0.3 & 0.3 \\
\hline Ring-beams & No & No & No & No \\
\hline \multirow[t]{2}{*}{ Typical building typologies } & All & All & Single house & $\begin{array}{l}\text { Terraced house } \\
\text { Apartment building }\end{array}$ \\
\hline & $1946-1960$ & & 1961-1980 & Post-1980 \\
\hline Material & Solid bricks & Hollow bricks & Hollow bricks & Hollow bricks \\
\hline Compressive strength (MPa) & 4.0 & 3.7 & 3.7 & 3.0 \\
\hline Tensile strength $(\mathrm{MPa})$ & 0.14 & 0.27 & 0.3 & 0.33 \\
\hline Specific density $\left(\mathrm{kg} / \mathrm{m}^{3}\right)$ & 1800 & 1500 & 1500 & 1200 \\
\hline Floor type & RC and hollow-tile & RC and hollow-tile & RC and hollow-tile & RC and hollow-tile \\
\hline Friction coefficient $(-)$ & 0.6 & 0.6 & 0.6 & 0.6 \\
\hline Ring-beams & Every floor & Every floor & Every floor & Every floor \\
\hline Typical building typologies & $\begin{array}{l}\text { Single house } \\
\text { Public housing }\end{array}$ & $\begin{array}{l}\text { Terraced house } \\
\text { Apartment building }\end{array}$ & All & All \\
\hline
\end{tabular}

information identified for each construction age. Table 2 summarises the reference information of the preeminent construction typologies, in the form used for implementation in Vulnus_4.0. Type and properties of materials, type of floors, effectiveness of wall-floor connections (represented in a simplified manner through a friction coefficient) and presence of curbs are some of the main data.

Whereas for the construction age Pre-1919, due to the very high local variability of construction practices (as above-mentioned), the main source of geometrical schemes for representative buildings was constituted by direct surveys and design project for structural interventions, for the following ages it was possible to resort to a broader series of sources.

For the period 1919-1945, various projects (with geometric, typological-constructive and material information) were organized in some project collection books (in Italian), such as "Villas - 68 Examples of villas and country houses" (Moretti 1946), "Dwelling houses in Italy" (Moretti 1947) and others.

In the following period, 1946-1960, public housing projects became very popular, therefore much information was selected from the projects related to the State intervention plan "INA-Casa", aimed at increasing the post-war workers' occupation, collected in the "Ridolfi Fund" (collection of documents about the professional activity of the Architect M. Ridolfi, from 1923 to 1984, preserved at the National Academy of Saint Luca, in Rome; some of these documents are also available online, at www.fondoridolfi.org).

Still for the period 1946-1960, as well as for the following one, 1961-1980, many private residential building projects were collected from the digital archive of the technical offices of some Italian municipalities. 
For the last construction age, Post-1980, many case studies were defined based on the significant information available on the websites of the leading Real Estate Agencies.

Then, to complete the sample and meet the representativeness criteria, some projects were specifically searched, based on the age and type of building, and identified thanks to the valuable support of some engineering companies and design firms. Lastly, other useful documents were the various editions of the manual "Composition of the house" (Ceccarini 1952 and subsequent editions up to 1985), which provide typological examples of Italian buildings throughout the first eight decades of the twentieth century.

As an example, Fig. 3 shows some of the typical URM buildings of the Italian residential heritage, for some construction periods and number of storeys.

\section{Vulnus-based seismic fragility model for moderate to severe damage}

The relevant information for each case study was implemented in Vulnus_4.0. As this software calculates fragility on discrete points, the discrete curves were replaced with cumulative probability logonormal functions - typically used to describe fragility and defined by only two parameters, i.e. mean $(\mu)$ and standard deviation $(\beta)$-through the maximum likelihood method, as shown in Fig. 4 for a case study.

No. storeys

1
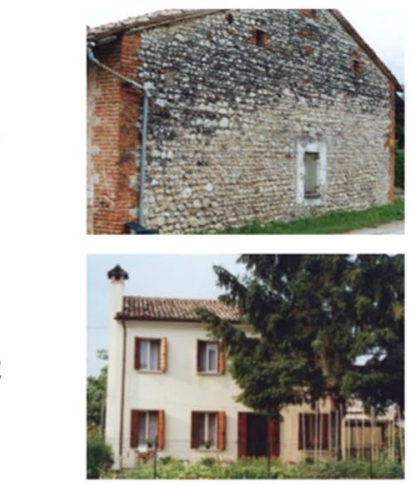

3
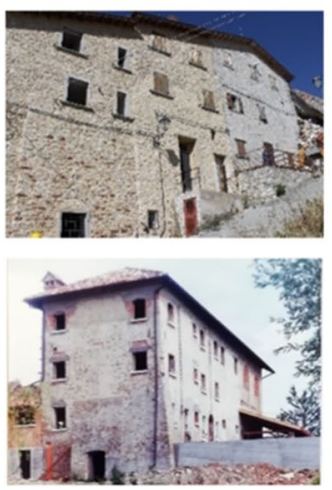

$1946-1960$
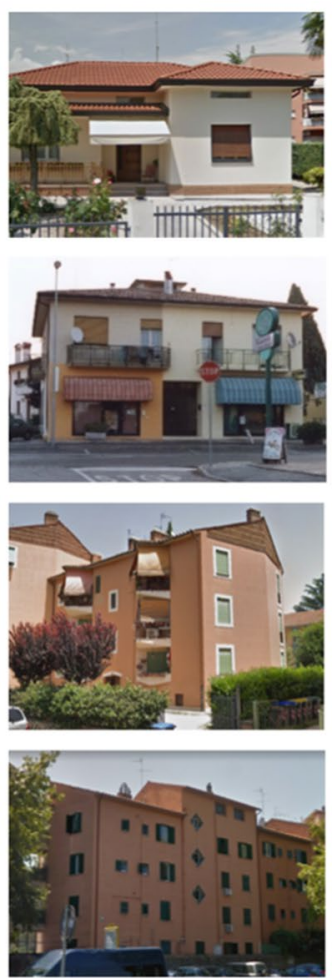

Post-1980
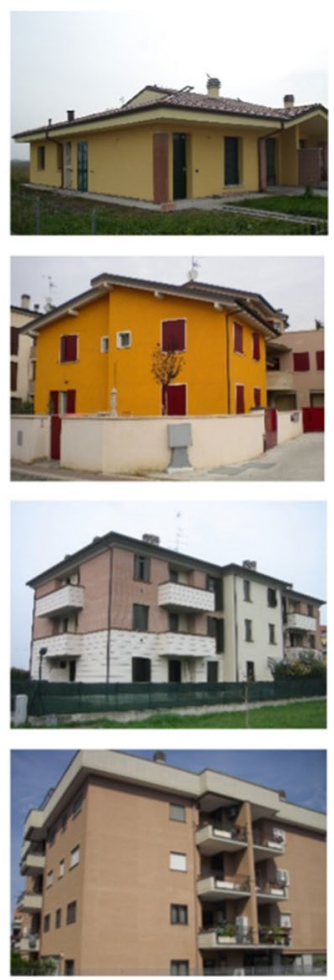

Fig. 3 Examples of some representative Italian URM buildings by construction age and number of storeys 
A first analysis based on these curves was aimed at assessing the adequacy of the database size. In particular, the effect of the sample size on the fragility curves was assessed by analysing, separately for each building macro-typology, ten random subsets of buildings with an increasing size, equal to $25 \%, 50 \%$ and $75 \%$ of the database. Some results (for three macro-typologies) are shown in Fig. 5, in terms of variation in both fragility curves and $\mu$ values, and show a clear convergence as the number of buildings analysed increases; more importantly, the maximum variation obtained with $75 \%$ of the database is relatively small for the purposes of this study, proving the adequacy of the database size.

Then, to determine the fragility of all building macro-typologies (Table 1), associated with a DS2-3 damage, the following procedure based on the logonormal curves of each building was followed:

- Step 1 Calculation of the average fragility curves for buildings classified by construction age (according to Table 1) and number of storeys (from one to five) at individual municipality level, for all the municipalities involved in the sampling.

- Step 2 Determination of the average fragility curves for buildings with the same construction age and number of storeys, through the simple average of the previous curves obtained for individual municipalities. This step, necessary to derive a model of general validity within the national territory, provides the same importance to the various construction typologies-within each building macro-typology-regardless of the actual number of buildings that for practical reasons were sampled in each municipality.

- Step 3 Derivation of the average fragility curves for all macro-typologies by weighted average of previous fragility curves (defined by period and number of storeys), separately for cases with buildings up to and with more than two storeys. The weights, depending on the number of storeys, are those derived from ISTAT data and shown in Fig. 1. This step is therefore essential to provide the fragility model with the characteristic of typological representativeness per macro-typology.

These steps were repeated separately for the White, Upper- and Lower-Bound curves. The described procedure is shown as an example in Fig. 6, which provides all the logonormal curves for the White fragility of buildings of the Pre-1919 period.

Fig. 4 Example of Vulnus curves and those obtained from logonormal fit

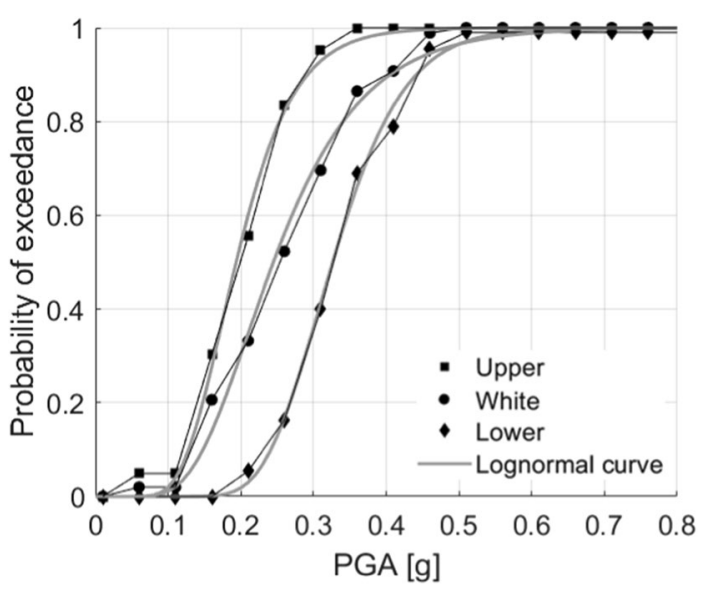

Springer 


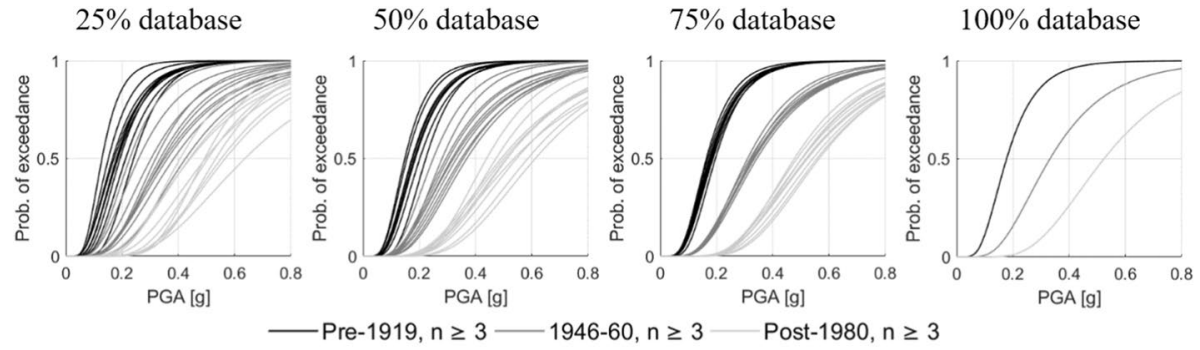

Pre-1919, $n \geq 3$
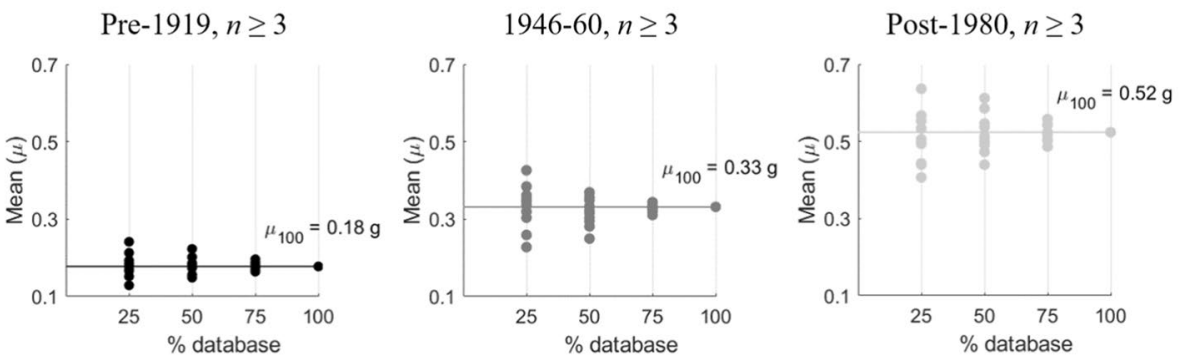

Fig. 5 Dependence of the fragility curves on the sample size, for three building macro-typologies

Figure 7 shows the complete model, i.e. considering all the building macro-typologies, for the White fragility. As can be seen, these macro-typologies allowed the definition of a fairly distributed fragility model, with probability of exceeding the given damage level that increases with increasing age and height of buildings. In particular, the greatest discontinuity in terms of fragility occurs between the periods 1919-1945 and 1946-1960, justified by the significant evolution of technology, construction techniques and material performances that occurred after the Second World War. Furthermore, the reduction of fragility due to the reduction in building height is more evident for more recent periods (1961-1980 and Post-1980), and this is reasonable considering the lower vulnerability of the most recent and newly designed buildings, which emphasizes their actual dynamic behaviour.

The complete model, with the White, Upper- and Lower-Bound fragility, is shown in Fig. 8, separately for each macro-typology. As can be seen, the dispersion range defined by the Upper- and Lower-Bound curves increases after 1946 and, in particular, is wider for the less vulnerable macro-typologies. This is related to a strong reduction in the LowerBound fragility, which is demonstrated in reality by the optimal seismic behaviour that recent URM buildings have, if properly designed and detailed for lateral loads (Penna et al. 2014; Sorrentino et al. 2019). The extent of dispersion is a useful information for territorial-scale risk assessments and, therefore, it will be duly taken into account.

\section{Multi-damage seismic fragility model}

The seismic risk management on a territorial scale requires accurate assessments of this risk (economic losses and casualties) to support the Civil Protection decision-making processes; therefore, it is necessary to provide fragility models that allow damage simulations 


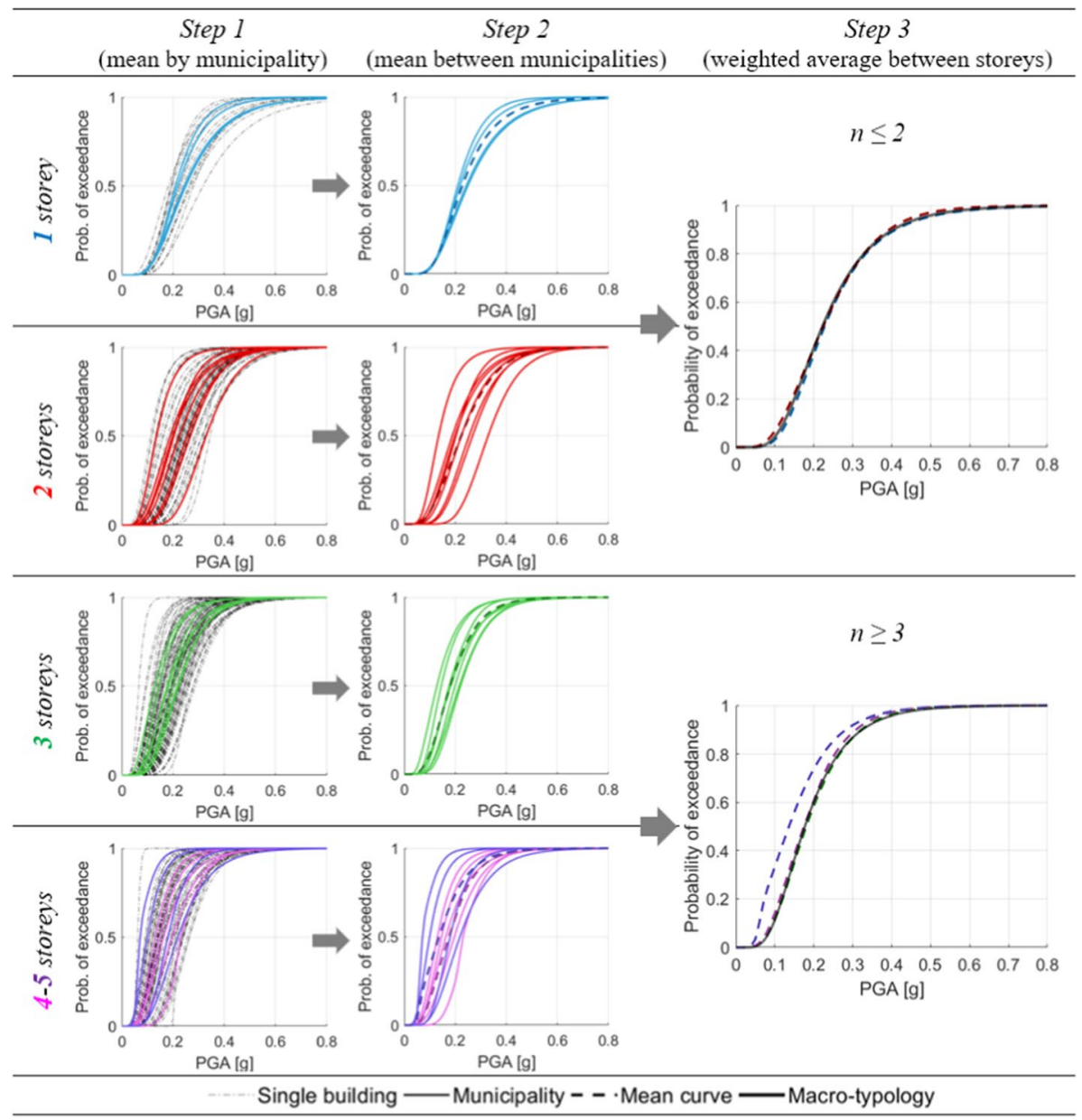

Fig. 6 Procedure to define fragility models. Example of White fragility for Pre-1919 buildings

with fairly distributed estimates. To this end, multi-damage fragility models, providing the exceeding probability for multiple damage levels (from the slight one to the building collapse), are desirable. Therefore, the Vulnus fragility model presented above was extended over the entire EMS98 damage scale (from DS1 to DS5) by using a heuristic approach based on previous relevant studies.

In particular, the fragility model proposed by Lagomarsino and Cattari (2014), which derives from the macroseismic approach of Lagomarsino and Giovinazzi (2006), was taken as a reference, as it is particularly suitable for our purposes. Indeed, it provides a distributed fragility based on the five DSs and the six vulnerability classes (from A to F) defined in EMS98, and therefore has general validity, referring to seismic performance categories rather than specific structural types.

Specifically, this model is based on the generic vulnerability curve proposed by Bernardini et al. (2011), which provides the mean damage $\mu_{D}$ as a function of the macroseismic intensity $I$ according to the following expression: 


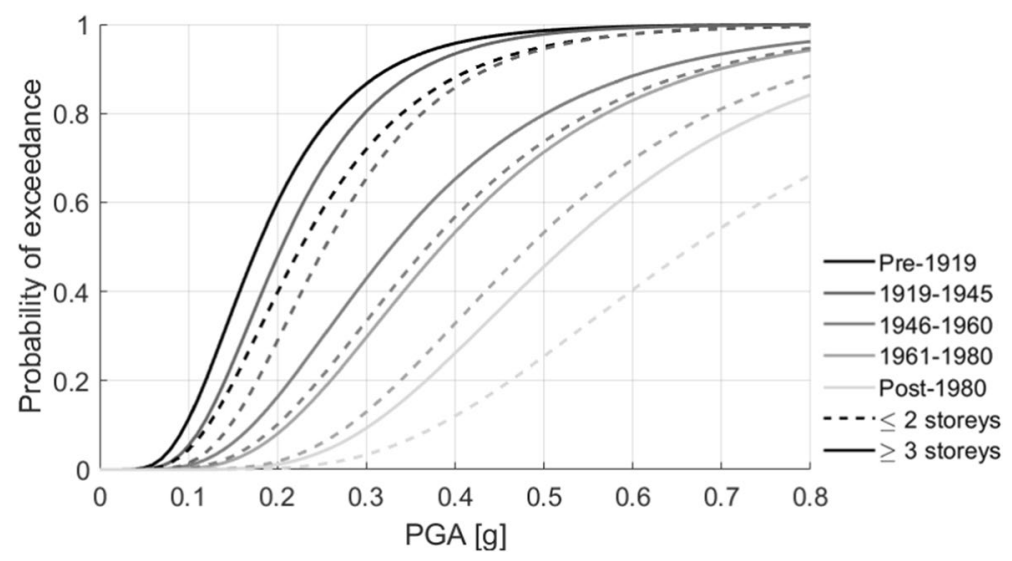

Fig. 7 Vulnus model of White fragility for all building macro-typologies

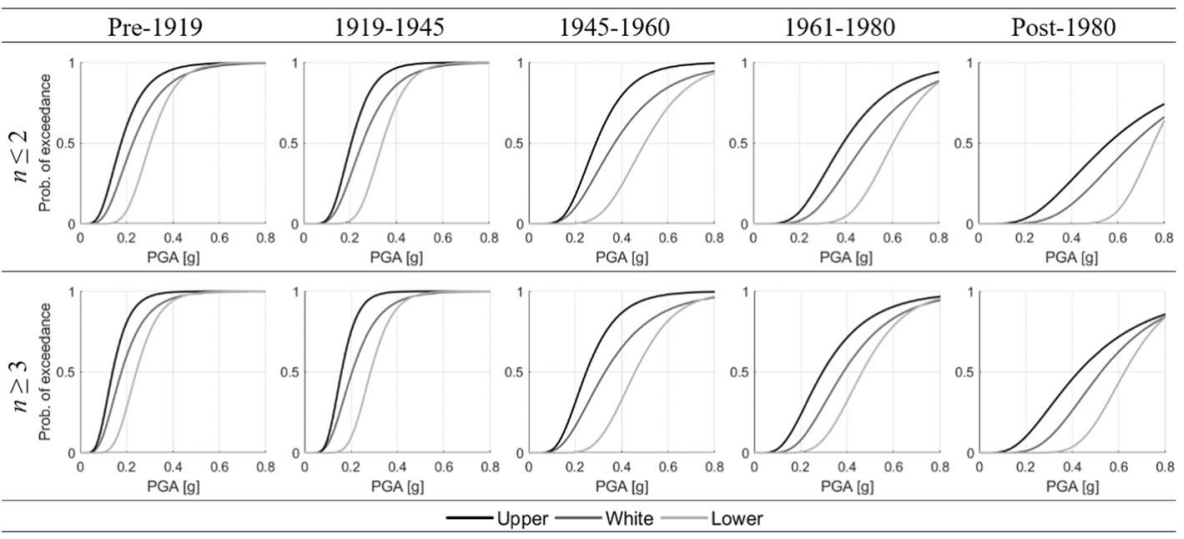

Fig. 8 White, Upper- and Lower-Bound fragility of all building macro-typologies

$$
\mu_{D}=2.5+3 \tanh \left(\frac{I+6.25 V-12.7}{Q}\right) \quad\left(0 \leq \mu_{D} \leq 5\right)
$$

In Eq. (1), $V$ is a vulnerability index whose values are provided in Lagomarsino and Cattari (2014) as confidence intervals for the six vulnerability classes, and $Q$ is a ductility parameter assumed equal to 3 by the same authors. Thus, assuming the binomial distribution, the fragility curves can be defined on the basis of $\mu_{D}$ and $I$ as:

$$
\begin{aligned}
& p_{L S k}=\sum_{i=k}^{5} p_{D S i} \quad(k=1, \ldots 5) \\
& p_{D S k}=\frac{5 !}{k !(5-k) !}\left(\frac{\mu_{D}(I)}{5}\right)^{k}\left(1-\frac{\mu_{D}(I)}{5}\right)^{5-k} \quad(k=0, \ldots 5)
\end{aligned}
$$


where $P_{D S k}$ is the probability of experiencing and $P_{L S k}$ the probability of exceeding the various damage states. To obtain the related fragility curves in terms of PGA, many correlation laws between PGA and $I$ are available in the literature, usually in the form:

$$
\log (P G A)=c_{1}+c_{2} I
$$

In this study, the mean values of $V$ were used for all vulnerability classes, and the parameters of the correlation law were assumed as $c_{1}=0.525$ and $c_{2}=0.22$, according to Margottini et al. (1992).

The main advantage to refer to such a model is thus the possibility of exploiting the fragility distribution with respect to the damage level, which is intrinsically defined by the EMS98 scale for each vulnerability class. Table 3 reports the mean $(\mu)$ and standard deviation $(\beta)$ values of this reference model.

Table 3 Mean $(\mu)$ and standard deviation $(\beta)$ values of reference fragility model

\begin{tabular}{|c|c|c|c|c|c|c|c|c|c|c|}
\hline \multirow[t]{2}{*}{$\begin{array}{l}\text { Vulner- } \\
\text { ability } \\
\text { class }\end{array}$} & \multicolumn{2}{|l|}{$\begin{array}{l}\text { DS1 } \\
\text { (slight) }\end{array}$} & \multicolumn{2}{|c|}{$\begin{array}{l}\text { DS2 } \\
\text { (moderate) }\end{array}$} & \multicolumn{2}{|c|}{$\begin{array}{l}\text { DS3 } \\
\text { (severe) }\end{array}$} & \multicolumn{2}{|c|}{$\begin{array}{l}\text { DS4 } \\
\text { (partial collapse) }\end{array}$} & \multicolumn{2}{|c|}{$\begin{array}{l}\text { DS5 } \\
\text { (complete col- } \\
\text { lapse) }\end{array}$} \\
\hline & $\mu(g)$ & $\beta(-)$ & $\mu(g)$ & $\beta(-)$ & $\mu(g)$ & $\beta(-)$ & $\mu(g)$ & $\beta(-)$ & $\mu(g)$ & $\beta(-)$ \\
\hline A & 0.0420 & 0.5110 & 0.0746 & 0.5331 & 0.1204 & 0.5278 & 0.1943 & 0.5332 & 0.3449 & 0.5120 \\
\hline B & 0.0693 & 0.5111 & 0.1230 & 0.5331 & 0.1986 & 0.5279 & 0.3209 & 0.5358 & 0.5822 & 0.5710 \\
\hline $\mathrm{C}$ & 0.1144 & 0.5111 & 0.2030 & 0.5331 & 0.3278 & 0.5285 & 0.5305 & 0.5411 & 0.9707 & 0.5859 \\
\hline D & 0.1887 & 0.5110 & 0.3349 & 0.5331 & 0.5408 & 0.5288 & 0.8732 & 0.5384 & 1.5693 & 0.5715 \\
\hline E & 0.3112 & 0.5092 & 0.5517 & 0.5293 & 0.8883 & 0.5230 & 1.4173 & 0.5257 & 2.452 & 0.5448 \\
\hline $\mathrm{F}$ & 0.5088 & 0.4881 & 0.8934 & 0.5060 & 1.4175 & 0.4984 & 2.1972 & 0.4951 & 2.3782 & 0.5358 \\
\hline
\end{tabular}
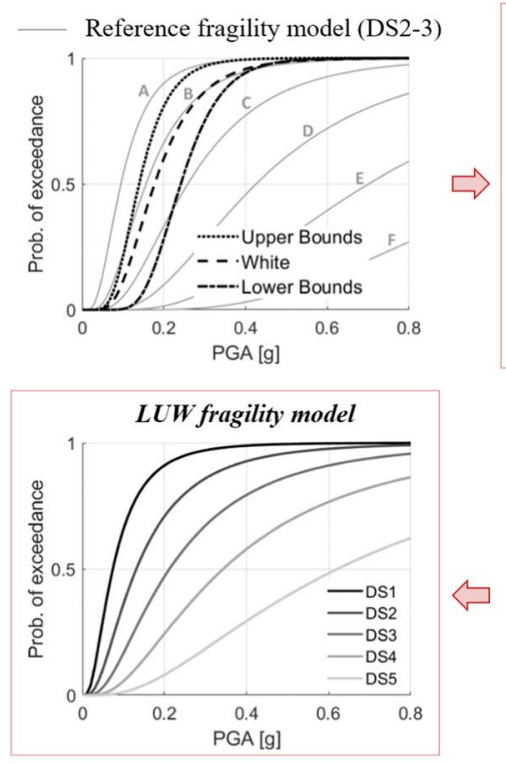

\section{Multi-damage fragility models}
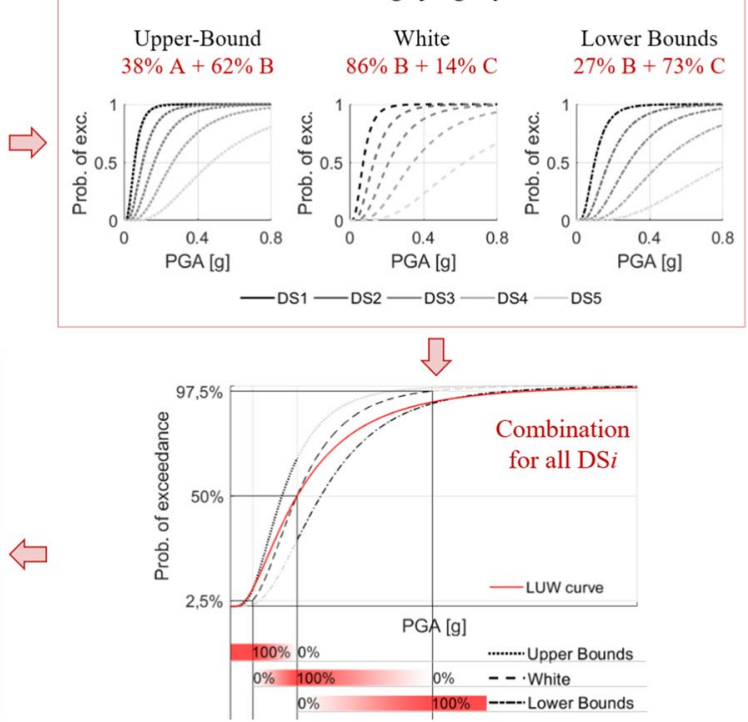

Fig. 9 Procedure to define multi-damage fragility models and LUW model. Example for Pre-1919, $n \geq 3$ 
Therefore, this reference model was calibrated on the derived Vulnus model to define the White, Upper- and Lower-Bound distributed fragility sets of each analysed building macro-typology. The main steps of the analysis are listed below and shown in Fig. 9.

- Step 1 For each vulnerability class (from A to F), an average fragility curve between those of DS2 and DS3 (DS2-3) was determined, which is consistent with the type of fragility described by the Vulnus model.

- Step 2 For each mechanical fragility curve of the Vulnus model (White, Upper- and Lower-Bound), the linear combination coefficients of the DS2-3 curves of the vulnerability classes were calculated, which provide the best fit of the combined curve on the mechanical one. To this end, a multi-objective problem was defined with the following aims: minimisation of the absolute error between the curves, according to the Least Squares Method and minimisation of the relative error, expressed as the difference between positive and negative areas bounded by the curves. The resolution of this problem was carried out through the NSGA-II genetic algorithm (Deb et al. 2002), obtaining a set of optimal solutions (or Pareto front). The final choice of the combination coefficients was made with expert judgment, evaluating the variability of the two types of error in the range of optimal solutions. Clearly, the optimization procedure is sensitive to the assumed range of PGA, as the latter influences the evaluation of errors between the curves. This range was extended up to $0.8 \mathrm{~g}$, which is a reasonable limit for the ground shaking in Italy, agreed in the project unanimously with the DPC. As an example, Fig. 10 shows the best match obtained between the White curves of the Vulnus model and the combined DS2-3 curves of the reference model. Table 4 reports all the optimal combination coefficients calculated.

- Step 3 Based on the parameters $\mu$ and $\beta$ (Table 3) and the combination coefficients (Table 4) of vulnerability classes, the White, Upper- and Lower-Bound fragility sets, defined on all DSs from DS1 to DS5, were derived for each building macro-typology.
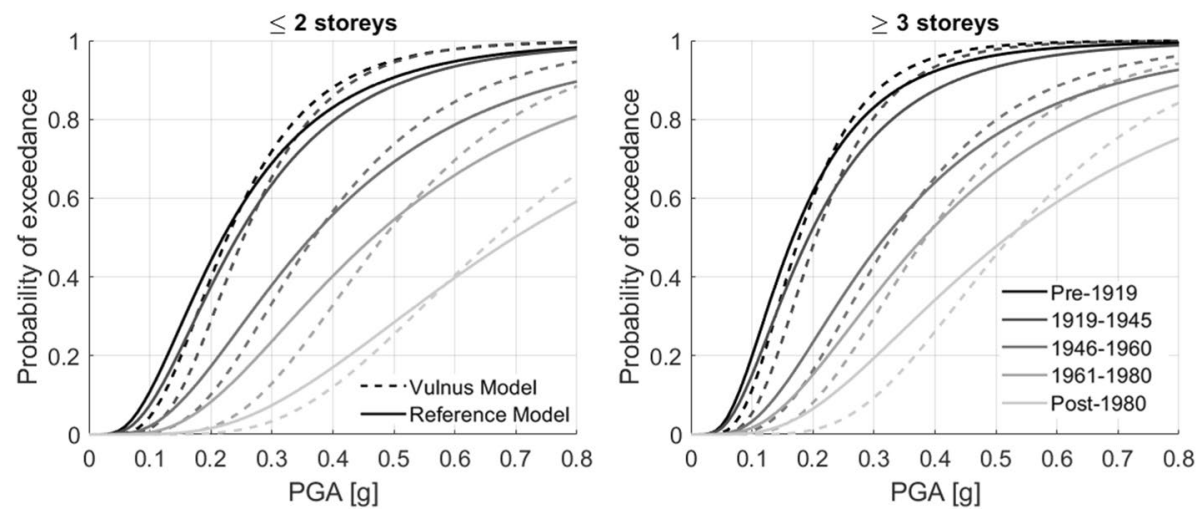

Fig. 10 Optimal fit of combined DS2-3 curves (reference model) on White curves (Vulnus model) 
Table 4 Optimal combination coefficients of vulnerability classes of reference model fitting Vulnus model

\begin{tabular}{|c|c|c|c|c|c|c|c|c|c|c|c|c|c|c|}
\hline \multirow{2}{*}{$\begin{array}{l}\text { Building } \\
\text { macro- } \\
\text { typologies }\end{array}$} & \multicolumn{5}{|c|}{ Upper-bound } & \multicolumn{4}{|c|}{ White } & \multicolumn{5}{|c|}{ Lower-bound } \\
\hline & A & B & $\mathrm{C}$ & $\mathrm{D}$ & $\mathrm{E}$ & B & $\mathrm{C}$ & $\mathrm{D}$ & $\mathrm{E}$ & B & $\mathrm{C}$ & $\mathrm{D}$ & $\mathrm{E}$ & $\mathrm{F}$ \\
\hline \multicolumn{15}{|l|}{ Pre-1919 } \\
\hline$n \geq 3$ & 0.38 & 0.62 & & & & 0.86 & 0.14 & & & 0.27 & 0.73 & & & \\
\hline$n \leq 2$ & & 0.87 & 0.13 & & & 0.33 & 0.67 & & & & 0.92 & 0.08 & & \\
\hline \multicolumn{15}{|l|}{ 1919-1945 } \\
\hline$n \geq 3$ & 0.15 & 0.85 & & & & 0.58 & 0.42 & & & 0.03 & 0.97 & & & \\
\hline$n \leq 2$ & & 0.62 & 0.38 & & & 0.13 & 0.87 & & & & 0.62 & 0.38 & & \\
\hline \multicolumn{15}{|l|}{$1946-1960$} \\
\hline$n \geq 3$ & & 0.16 & 0.84 & & & & 0.58 & 0.42 & & & & 0.95 & 0.05 & \\
\hline$n \leq 2$ & & & 0.94 & 0.06 & & & 0.32 & 0.68 & & & & 0.77 & 0.23 & \\
\hline \multicolumn{15}{|l|}{$1961-1980$} \\
\hline$n \geq 3$ & & & 0.77 & 0.23 & & & 0.23 & 0.77 & & & & 0.92 & 0.08 & \\
\hline$n \leq 2$ & & & 0.2 & 0.8 & & & & 0.81 & 0.19 & & & 0.17 & 0.83 & \\
\hline \multicolumn{15}{|l|}{ Post-1980 } \\
\hline$n \geq 3$ & & & & 1 & & & & 0.6 & 0.4 & & & 0.04 & 0.96 & \\
\hline$n \leq 2$ & & & & 0.44 & 0.56 & & & 0.01 & 0.99 & & & & 0.22 & 0.78 \\
\hline
\end{tabular}

The fragility sets thus obtained allow elaborating scenarios of distributed damage that can be considered as the most probable, when derived from White fragility, or extreme, when based on Upper- or Lower-Bound fragility.

Furthermore, the Upper- and Lower-Bound fragility sets define the dispersion of vulnerability information for each building macro-typology, which depends on the uncertainties at the individual building level (quantified through the Fuzzy theory as discussed in Sect. 2) and on the variability and extent of the sampled building stock. This information is very important, because the mechanics-based fragility curves are generally characterized by relatively low standard deviations $(\beta)$ in relation to the needs of large-scale vulnerability assessment. Indeed, the values of $\beta$ are generally lower than those of empirical approaches, calibrated on extended databases of observed damage. However, the empirical approaches include other sources of uncertainty, in addition to those relating to the variability of the
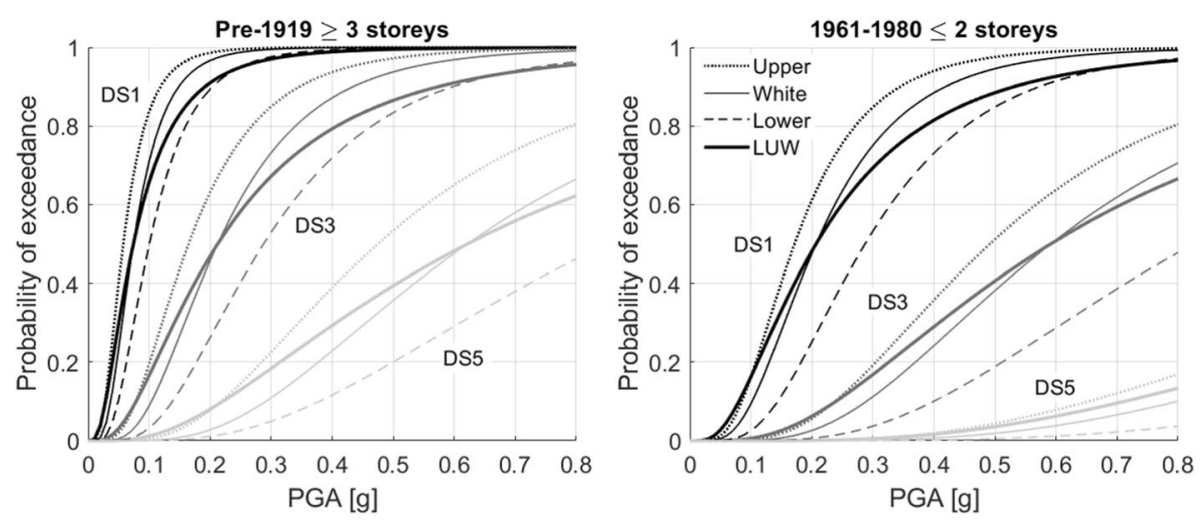

Fig. 11 Comparison between LUW curves and associated White, Upper- and Lower-Bound curves 
Table $5 \mu$ and $\beta$ values of LUW fragility model

\begin{tabular}{|c|c|c|c|c|c|c|c|c|c|c|}
\hline \multirow{2}{*}{$\begin{array}{l}\text { Building } \\
\text { macro- } \\
\text { typologies }\end{array}$} & \multicolumn{2}{|l|}{ DS1 } & \multicolumn{2}{|l|}{ DS2 } & \multicolumn{2}{|l|}{ DS3 } & \multicolumn{2}{|l|}{ DS4 } & \multicolumn{2}{|l|}{ DS5 } \\
\hline & $\mu(g)$ & $\beta(-)$ & $\mu(g)$ & $\beta(-)$ & $\mu(g)$ & $\beta(-)$ & $\mu(g)$ & $\beta(-)$ & $\mu(g)$ & $\beta(-)$ \\
\hline \multicolumn{11}{|l|}{ Pre-1919 } \\
\hline$n \geq 3$ & 0.0741 & 0.7414 & 0.1315 & 0.7671 & 0.2123 & 0.7759 & 0.3430 & 0.7736 & 0.6215 & 0.8090 \\
\hline $\begin{array}{l}n \leq 2 \\
1919-1945\end{array}$ & 0.0973 & 0.6929 & 0.1726 & 0.7084 & 0.2787 & 0.7192 & 0.4507 & 0.7499 & 0.8217 & 0.7936 \\
\hline$n \geq 3$ & 0.0854 & 0.7293 & 0.1516 & 0.7431 & 0.2447 & 0.7479 & 0.3955 & 0.7700 & 0.7168 & 0.8204 \\
\hline $\begin{array}{l}n \leq 2 \\
1946-1960\end{array}$ & 0.1076 & 0.7388 & 0.1908 & 0.7533 & 0.3082 & 0.7474 & 0.4988 & 0.7563 & 0.9140 & 0.7924 \\
\hline$n \geq 3$ & 0.1409 & 0.7489 & 0.2501 & 0.7780 & 0.4039 & 0.7789 & 0.6526 & 0.7975 & 1.1840 & 0.7452 \\
\hline $\begin{array}{l}n \leq 2 \\
1961-1980\end{array}$ & 0.1613 & 0.7651 & 0.2862 & 0.7791 & 0.4625 & 0.7818 & 0.7496 & 0.8015 & 1.3660 & 0.6933 \\
\hline$n \geq 3$ & 0.1689 & 0.6770 & 0.2996 & 0.7070 & 0.4842 & 0.7388 & 0.7855 & 0.7875 & 1.4350 & 0.6997 \\
\hline$n \leq 2$ & 0.2067 & 0.7366 & 0.3669 & 0.7367 & 0.5913 & 0.7069 & 0.9499 & 0.6916 & 1.6930 & 0.6764 \\
\hline Post-1980 & & & & & & & & & & \\
\hline$n \geq 3$ & 0.2301 & 0.6945 & 0.4083 & 0.7120 & 0.6580 & 0.6874 & 1.0550 & 0.6240 & 1.8690 & 0.5982 \\
\hline$n \leq 2$ & 0.3098 & 0.7918 & 0.5492 & 0.7429 & 0.8849 & 0.7393 & 1.4160 & 0.6780 & 2.4700 & 0.6132 \\
\hline
\end{tabular}

building stock (e.g., uncertainties on the damage surveys and the ground acceleration measures), and could therefore provide overestimates of $\beta$.

Based on this, and considering the aim of providing a practical tool for large-scale risk assessments, a single fragility set for each building macro-typology, named as LUW, was finally derived by using the main information of the White, Upper- and Lower-Bound fragility sets. The criterion used was to calibrate the mean fragility on that of the White set and the standard deviation on the maximum dispersion provided by the Upper- and LowerBound sets, thus obtaining a more suitable model to describe the fragility of the building heritage. The followed procedure is described below and shown in Fig. 9.

When the White probability is:

- lower than $2.5 \%$, fragility is assumed equal to the Upper-Bound one;

- between $2,5 \%$ and $50 \%$, fragility is calculated as a linear combination of Upper-Bound (from 100 to $0 \%$ ) and White (from 0 to $100 \%$ ) fragility;

- between $50 \%$ and $97.5 \%$, fragility is calculated as a linear combination of White (from 100 to $0 \%$ ) and Lower-Bound (from 0 to $100 \%$ ) fragility;

- greater than $97.5 \%$, fragility is assumed equal to the Lower-Bound one.

The LUW curves were first obtained by discrete points, and subsequently converted into logonormal curves by applying the criterion of maximum likelihood in the PGA range of interest, i.e. from 0 to $0.8 \mathrm{~g}$. As an example, Fig. 11 shows some comparisons between the proposed LUW model and the White, Upper- and Lower-Bound fragility sets, from which it derives. Table 5 lists the $\mu$ and $\beta$ values of the entire LUW model, i.e. for all building macro-typologies and DSs; the related fragility curves are shown in Fig. 12. 

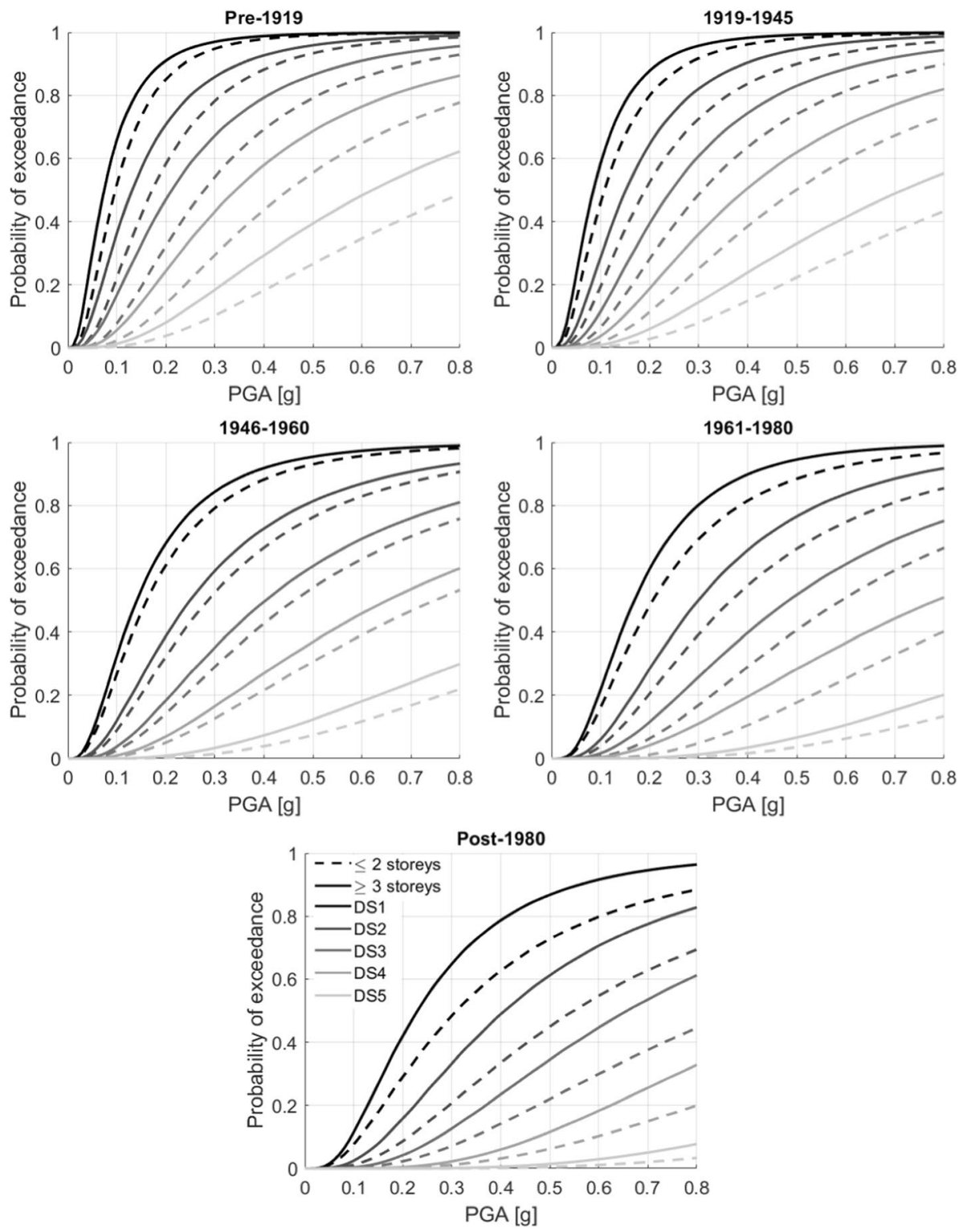

Fig. 12 Fragility sets (from DS1 to DS5) of LUW model of all building macro-typologies

\section{Reliability assessment of the proposed model based on the observed damage}

For damage simulation and risk assessment in a given territory, it is necessary to know data about its building stock, in terms of belonging to a certain macro-typology and location, and its seismic hazard. To calculate the risk, this information must be processed according to the total probability theorem, which consists of the integration of the three probability 
functions of vulnerability, hazard and exposure. In the absence of a cost model (generally based on the level of damage), needed to fully define the exposure data, the procedure will provide estimates of damage instead of risk.

This information at national level is provided by ISTAT for what concerns the building stock, and by INGV (National Institute of Geophysics and Volcanology) for what concerns the hazard. The information is collected and organized in I.R.MA platform (Eucentre 2018), developed by the European Centre for Training and Research in Earthquake Engineering (Eucentre) in collaboration with the DPC. I.R.MA's objective is to provide researchers with an open, common and verified risk assessment tool that allows implementing user-defined models of fragility, cost and casualties. In addition, I.R.MA contains information on the ground shaking accelerations (ShakeMaps) of some recent and significant Italian earthquakes, and thus allows simulating specific seismic events and calculating a posteriori damage and costs. This is a very useful tool for validating or even calibrating the various fragility models to be implemented in I.R.MA.

Therefore, to assess the reliability of the fragility model proposed in this study, the model was implemented in I.R.MA and was applied to simulate the 2009 L'Aquila earthquake, obtaining the related damage scenarios. Besides being one of the most devastating Italian events in recent years, the L'Aquila earthquake is the most suitable for validation purposes, due to the completeness and reliability of the related information on damage observed and ground shaking.

Damage data relating to this event was obtained from Da.D.O. (Dolce et al. 2019), a database of the DPC that collects, in a digital form, the damage information detected in the aftermath of the various earthquakes. In particular, for the 2009 L'Aquila earthquake and afterwards, the damage surveys were based on the latest review of the AeDES form (Baggio et al. 2007). This form requires, in addition to the main information on the building (age, material, purpose of use, etc.), the identification of the DSs and of their extension-with respect to the entire building, parameter " $e$ "- for the main structural and non-structural elements. In addition, a judgment on safety and usability, based on the damage detected, is required. The damage metric is based on the EMS98 scale but the DSs are merged as follow: DS0 (no damage), DS1 (slight), DS2-DS3 (moderate), DS4-DS5 (severe). As for the extent of damage, the metric is: $e<1 / 3,1 / 3<e<2 / 3, e>2 / 3$.

Based on the AeDES information, various methods were developed in recent years to define a single and equivalent level of damage per inspected building, in order to evaluate and represent damage scenarios and to support calibrations of empirical fragility models. In general, two methodologies can be distinguished: one is based on the weighted average of damage of the various building elements (Di Pasquale and Goretti 2001; Lagomarsino et al. 2015), whereas the other rewards the maximum damage among these elements (Rota et al. 2008; Dolce and Goretti 2015). To validate the fragility model, both methodologies were considered, applying the methods of Lagomarsino et al. (2015) and Rota et al. (2008).

The method of Lagomarsino et al. (2015) first requires calculating the equivalent damage $d_{j}$ for the main building elements (vertical structures, floors, roof), according to Eq. (4), where the coefficients of intensity $d_{i}$ and extension $e_{i}$-defining the possible damage suffered by a given element-are assumed as in Table 6, based on the AeDES information. Then, the overall building damage $D_{b}$ is obtained as a weighted average of the previous $d_{j}$ according to Eq. (5), where the weights $\alpha_{i}$ are given in Table 7 . These weights vary depending on whether the damage survey is complete or partial (only external), for obvious reasons. In the case of partial survey but complete information, albeit indirect, Lagomarsino et al. (2015) suggest using both sets of $\alpha_{i}$ and taking the 
Table $6 d_{i}$ and $e_{i}$ coefficients associated with AeDES information (Lagomarsino et al. 2015)

Table $7 \alpha_{i}$ weights associated with building elements (Lagomarsino et al. 2015)

\begin{tabular}{lllll}
\hline $\begin{array}{c}\text { Damage inten- } \\
\text { sity (AeDES) }\end{array}$ & DS0 & DS1 & DS2-DS3 & DS4-DS5 \\
$d_{i}$ & 0 & 1 & 2.5 & 4.5 \\
$\begin{array}{c}\text { Damage exten- } \\
\text { sion (AeDES) }\end{array}$ & & $e<1 / 3$ & $1 / 3<e<2 / 3$ & $e>2 / 3$ \\
$e_{i}$ & 0.33 & 0.66 & 1 \\
\hline
\end{tabular}

\begin{tabular}{lll}
\hline Elements $(j)$ & Complete survey & $\begin{array}{l}\text { Partial survey } \\
\text { (external) }\end{array}$ \\
\hline Vertical structures & 0.6 & 0.8 \\
Floors & 0.2 & 0 \\
Roof & 0.2 & 0.2 \\
\hline
\end{tabular}

highest $D_{b}$. The obtained $D_{b}$ values were rounded to the next unit, and thus converted into the EMS98 scale.

$$
\begin{gathered}
d_{j}=\sum_{i} d_{i} e_{i} \\
D_{b}=\sum_{j} \alpha_{j} d_{j}
\end{gathered}
$$

The method of Rota et al. (2008) consists in converting the AeDES damage information into the EMS98 metric, according to Table 8, separately for vertical structures, floors and roof. Subsequently, the damage levels of the various building elements are compared and the maximum is taken as the overall building damage.

As above mentioned, the AeDES information relating to the 2009 L'Aquila earthquake was analysed according to these two methods. It is important to point out that, although the damage survey was extensive, it was not complete in all the Municipalities affected by the seismic event. In addition, some AeDES forms did not provide specifications on the type of use and construction material of the building, therefore they were excluded from the creation of damage scenarios for residential masonry buildings.

Hence, the available information was assessed with respect to the total number of residential buildings of each municipality (according to ISTAT information), to provide an indication of reliability. In particular, Fig. 13a identifies the municipalities where damage surveys were available for less than 30\%, between 30 and $90 \%$ and more than $90 \%$ of buildings. As can be seen, the municipalities near the epicentre were almost completely surveyed, thus they provide a robust and reliable information; moving away from the epicentre, the percentage of inspected buildings is clearly smaller, and the information is less reliable. For the purposes of this study, the share of uninspected buildings was associated with DS0. This assumption seems to be reasonable for the L'Aquila earthquake, where the lack of surveys may be related to the absence of damage on the building. However, some of these buildings may have suffered minor damage, not surveyed via the AeDES form for various and specific reasons, and this represents a source of uncertainty. Figure 13b shows the ShakeMap of the main event of 06 April 2009 (available on the INGV website). 
Table 8 Convertion of AeDES damage information to EMS98 damage scale (Rota et al. 2008)

\begin{tabular}{lllllllll}
\hline AeDES & DS0 & DS1 & DS2-DS3 & & & DS4-DS5 \\
to & & & $e<1 / 3$ & $1 / 3<e<2 / 3$ & $e>2 / 3$ & $e<1 / 3$ & $1 / 3<e<2 / 3$ & $e>2 / 3$ \\
EMS98 & DS0 & DS1 & DS2 & DS3 & DS3 & DS4 & DS4 & DS5 \\
\hline
\end{tabular}

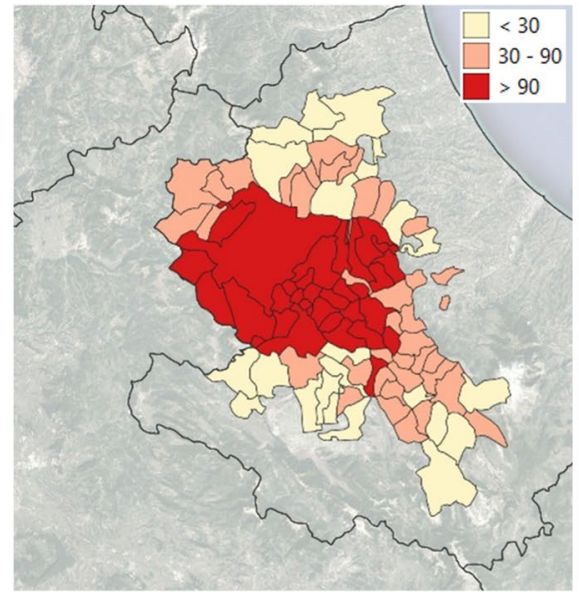

(a)

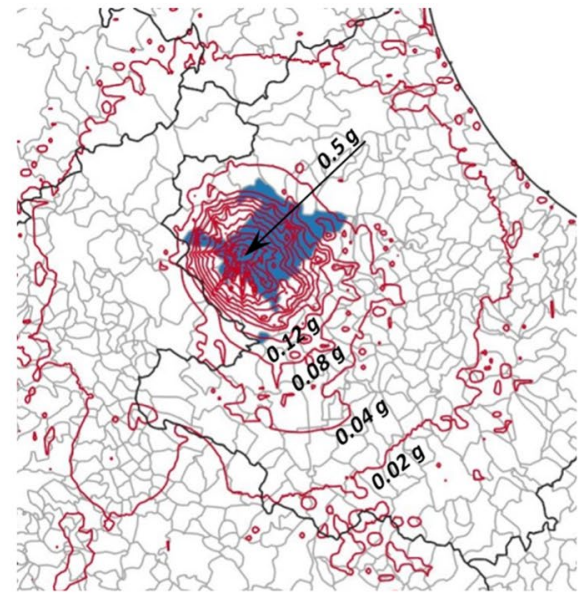

(b)

Fig. 13 a \% of surveyed buildings of all municipalities; b ShakeMap of L'Aquila 2009

Figure 14 shows the comparison between the simulated damage scenarios, obtained with the proposed fragility model, and the observed damage scenarios, elaborated with the above-mentioned methods. In particular, these scenarios provide the percentage of buildings that reach or exceed a given DS for each municipality affected by the earthquake. The following considerations can be drawn.

- For all DSs, the trend of the simulated damage is similar to that of the observed damage; in addition, the damage values predicted by the proposed fragility model are substantially in-between the observed damage values measured with the two methods of Lagomarsino et al. (2015) and Rota et al. (2008), with the exception of some epicentral municipalities that show a slightly conservative damage prediction, in particular for DS1.

- The two methods for measuring the observed damage reasonably lead to quite different scenarios, as that of Lagomarsino et al. (2015) rewards average building damage whereas that of Rota et al. (2008) rewards the damage peaks detected in the building. This aspect is interesting and underlines the practical difficulty of describing the overall damage of a building in a univocal and simplified way (i.e., with a single parameter), being able also to rely on an accurate damage survey.

- The proposed fragility model returns damage estimates that most closely resemble those obtained with the method that rewards maximum damage, near the epicentre (i.e., for high PGA values) and those obtained with the method that rewards average damage, 

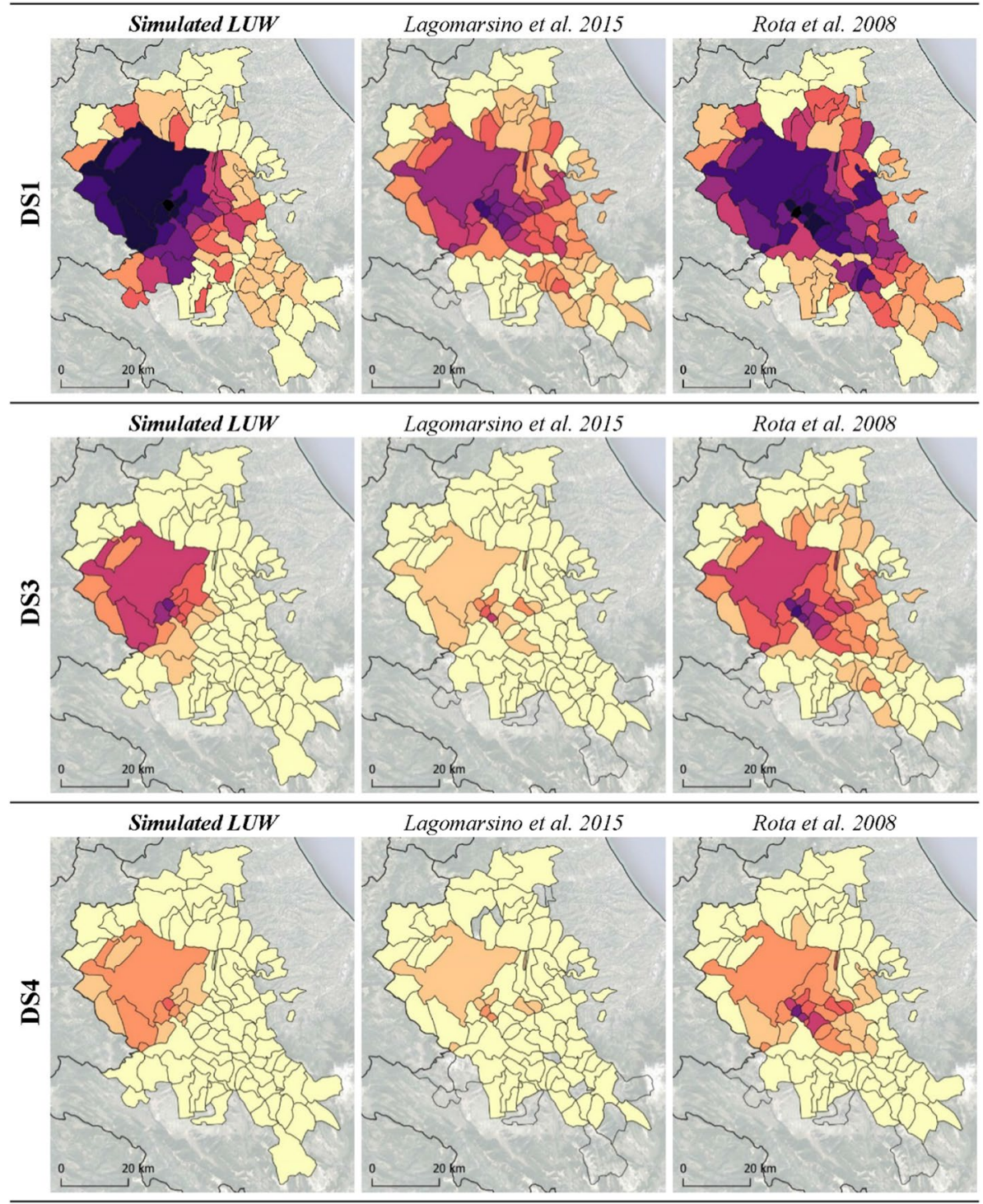

Percentage of buildings per municipality that reaches or exceeds DS $i$ :

$\square 0-10 \square 10-20 \square^{20-30} \square^{30-40} \square{ }^{40-50} \square{ }^{50-60} \square{ }^{60-70} \square{ }^{70-80} \square_{80-90} \square_{90-100}$

Fig. 14 Simulated and observed damage scenarios of the 2009 L'Aquila earthquake

moving away from the epicentre (i.e., for lower PGA values). This is due to the intrinsic characteristics of mechanics-based fragility, i.e. to the relatively low standard deviation of logonormal curves, an aspect taken into account in this study and mitigated using the dispersion given by the Upper- and Lower-Bound fragility curves. 

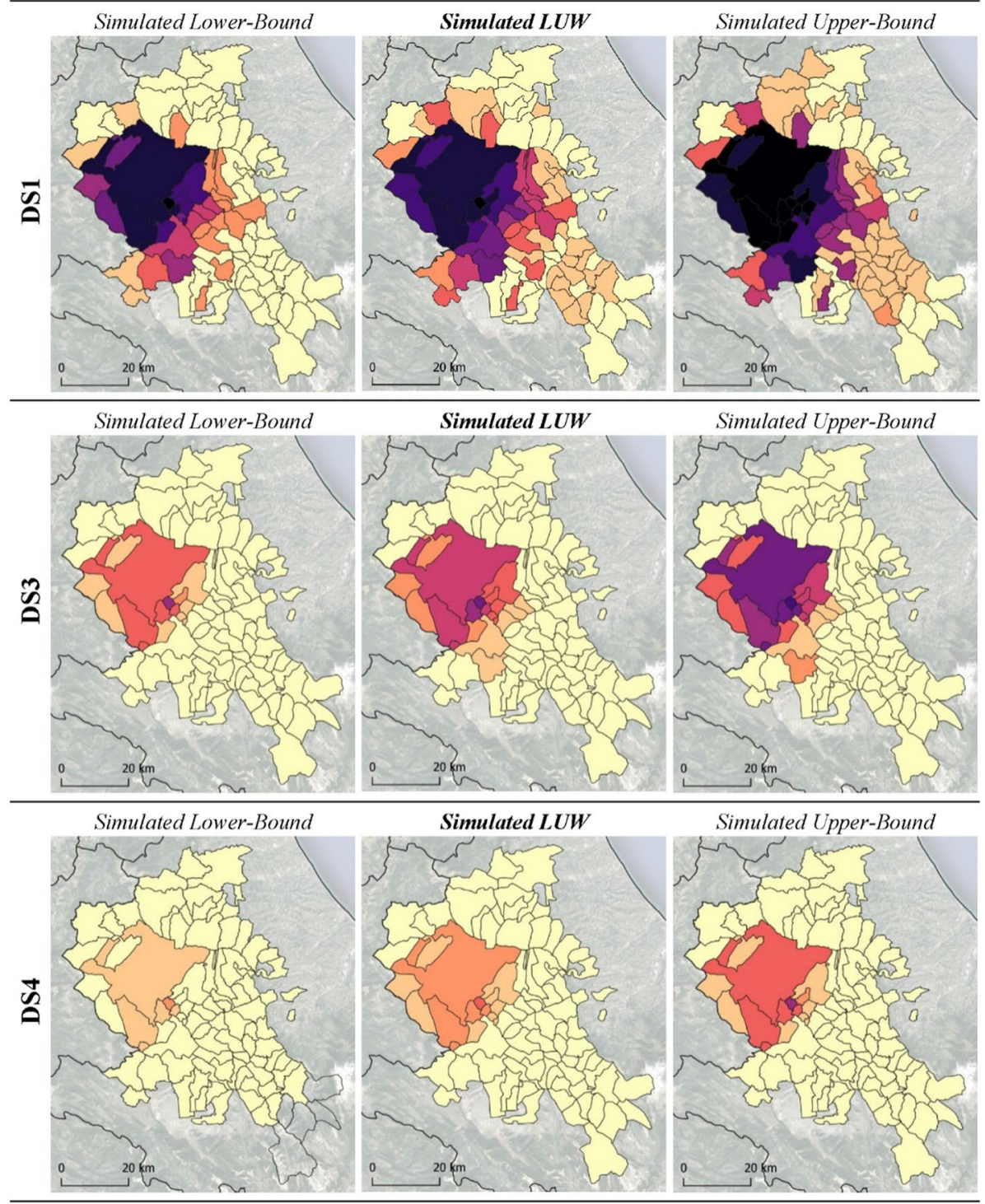

Percentage of buildings per municipality that reaches or exceeds DS $i$

$\square$ 0-10 $\square$ 10-20 $\square^{20-30} \square^{30-40} \square^{40-50}{ }^{50-60} \square_{60-70} \square_{70-80} \square_{80-90} \square 90-100$

Fig. 15 Comparison of damage scenarios simulated by the LUW, Upper- and Lower-Bound models

It is worth noting that some differences between simulated and observed damage are also due to the reasonable limitation of I.R.MA to use the PGA recorded in the centroid of the municipality for the whole municipal territory, which could be particularly limiting for larger municipalities or for any municipality having strong variations in soil characteristics.

Finally, Fig. 15 shows the comparisons between the most likely damage scenarios, simulated with the LUW model, and those obtained by applying the Upper- and 
Lower-Bound fragility models, which allow to evaluate the maximum expected damage interval due to the various uncertainties at stake.

\section{Conclusions}

A mechanics-based seismic fragility model was developed and proposed for territorialscale vulnerability assessment of the Italian residential masonry heritage. This model is based on the classification of the masonry building stock in ten macro-typologies, defined by age of construction and number of storeys, which are information available at national level (collected by census by the national agency, ISTAT).

This model is calibrated on the fragility of over 500 buildings, sampled following the criteria of geographical and typological representativeness at national level, and analysed through the Vulnus_4.0 software. These analyses led to the definition of a first model, called Vulnus model, which gives the exceedance probabilities of a damage state (DS) between moderate and severe (DS2-3 according to the EMS98 damage scale) for all identified building macro-typologies. The Vulnus model was then extended to all DSs of the EMS98 scale (from slight damage DS1 to total collapse DS5) on the basis of a reference model available in the literature, which provides the fragility of the various vulnerability classes of the EMS98 scale. Lastly, in the calculation of the final logonormal fragility curves, the dispersion related to the uncertainties, for each building, on the collected information was also taken into account.

To assess the reliability of the proposed fragility model, this was used to simulate damage scenarios due to the 2009 L'Aquila earthquake, calculating the percentages of buildings with damage equal to or greater than the various DSs considered, for each municipality struck by the earthquake. The results were compared with the observed damage, which was measured with two different methods, based respectively on the average or maximum damage among the main building elements. The comparison proved the effectiveness of the proposed model, which gave damage information similar to that detected on-site. In particular, the model results were very similar to the measures of maximum damage in the epicentric municipalities (greater PGAs), and to the measures of average damage moving away from the epicentre (lower PGAs).

Damage prediction is essential for subsequent risk estimates, as economic losses and casualties require additional models expressed as a function of the estimated damage. From the comparisons of simulated and observed damage we can conclude that the proposed model seems suitable for risk estimates. Indeed, casualties correlate with the highest DSs and thus, in general, with higher PGAs, for which the model better predicts the damage peaks in buildings. Economic losses are very intense in the case of intermediate and more probable PGAs, for which the model better predicts the average damage in buildings.

Although the results are encouraging, the awareness of the complexity of this study and the uncertainties characterising all the steps to derive the proposed model suggest using it with due care, highlighting its great potential for improvement.

In particular, one of the main assumptions of this work was the average of the fragility curves of the individual municipalities, so as to derive a model of general validity within the national territory (rather than various models calibrated on specific geographical areas). Therefore, future studies will be aimed at refining the macro-typological classification, with particular attention to geographical representativeness, in order to provide a possible regionalisation of the proposed model through a more rational weighted average 
of the fragility curves of specific territorial areas. To this end, the database of the buildings analysed will also be increased and the variation in fragility due to typical seismic retrofit interventions (widely applied in some of the areas affected by previous earthquakes) will also be assessed. All this aims to provide increasingly reliable territorialscale damage assessment tools, necessary for national risk management purposes.

Acknowledgements Special thanks are due to the Italian Civil Protection Department, ReLUIS and Eucentre-for having motivated the realization of this work and for coordinating the Work Group on the seismic vulnerability assessment of the Italian residential heritage - and to the entire Work Group for useful advice and discussions that raised the quality of this study.

Author's contribution MD: Conceptualization, methodology, validation, writing-original draft. PC: Formal analysis, investigation. VF: Formal analysis, visualization. LS: Data curation. FdP: Conceptualization, writing-review \& editing, supervision.

Funding Open access funding provided by Università degli Studi di Padova within the CRUI-CARE Agreement. This research did not receive any specific grant from funding agencies in the public, commercial, or not-for-profit sectors.

Availability of data and materials Some or all data, models, or code that support the findings of this study are available from the corresponding author upon reasonable request.

\section{Compliance with ethical standards}

Conflict of interest The authors declare that they have no conflict of interest.

Open Access This article is licensed under a Creative Commons Attribution 4.0 International License, which permits use, sharing, adaptation, distribution and reproduction in any medium or format, as long as you give appropriate credit to the original author(s) and the source, provide a link to the Creative Commons licence, and indicate if changes were made. The images or other third party material in this article are included in the article's Creative Commons licence, unless indicated otherwise in a credit line to the material. If material is not included in the article's Creative Commons licence and your intended use is not permitted by statutory regulation or exceeds the permitted use, you will need to obtain permission directly from the copyright holder. To view a copy of this licence, visit http://creativecommons.org/licenses/by/4.0/.

\section{References}

Arosio G (1941) Enciclopedia del costruttore edile, Hoepli (in Italian)

Baggio C, Bernardini A, Colozza R, Corazza L, Della Bella M, Di Pasquale G, Dolce M, Goretti A, Martinelli A, Orsini G, Papa F, Zuccaro G (2007) Field manual for post-earthquake damage and safety assessment and short-term countermeasures (AeDES). Translation from Italian: Rota M, Goretti A. JRC Scientific and Technical Reports, EUR 22868 EN-2007

Bernardini A (2000) La vulnerabilità degli edifici. Valutazione a scala nazionale della vulnerabilità degli edifici ordinari. CNR - Gruppo Nazionale per la Difesa dai Terremoti

Bernardini A, Tonon F (2004) Aggregation of evidence from random and fuzzy sets. ZAMM J Appl Math Mech 84(10-11):700-709

Bernardini A, Gori M, Modena C (1990) Application of coupled analytical models and experimental kowledge to seismic vulnerability analyses of masonry buildings. In: Koridze A (ed) Earthquake damage evaluation and vulnerability analysis of building structures. INEEC, Omega Scientific, Ozon, pp $161-180$

Bernardini A, Valluzzi MR, Modena C, D’Ayala D, Speranza E (2008) Vulnerability assessment of the historical masonry building typologies of Vittorio Veneto (NE Italy). Bollettino di Geofisica Teorica ed Applicata 49:n. 3-4, pp. 463-483 
Braga F, Gigliotti R, Monti G, Morelli F, Nuti C, Salvatore W, Vanzi I (2014) Speedup of post earthquake community recovery: the case of precast industrial buildings after the Emilia 2012 earthquake. Bull Earthq Eng 12(5):2405-2418

Cacace F, Zuccaro G, De Gregorio D, Perelli FL (2018) Building Inventory at National scale by evaluation of seismic vulnerability classes distribution based on Census data analysis: BINC procedure. Int J Disaster Risk Reduct 28:384-393

Calvi GM, Pinho R, Magenes R, Bommer JJ, Restrepo-Veléz LF, Crowley H (2006) The development of seismic vulnerability assessment methodologies for variable geographical scales over the past 30 years. ISET J Earthq Technol 43(3):75-104

Campostrini GP, Taffarel S, Bettiol G, Valluzzi MR, da Porto F, Modena C (2017) A Bayesian approach to rapid seismic vulnerability assessment at urban scale. Int J Archit Herit 12(1):36-46

Cantalupi A (1862) Istruzioni pratiche sull'arte di costruire le fabbriche civili. Galli e Omodei Editori Librai Milano (in Italian)

Carbonara P (1954) Trattato di architettura pratica, Utet (in Italian)

Ceccarini I (1952) Composizione della casa, Hoepli (in Italian)

Cescatti E, Salzano P, Casapulla C, Ceroni F, da Porto F (2019) Prota A (2019) Damages to masonry churches after 2016-2017 Central Italy seismic sequence and definition of fragility curves. Bull Earthq Eng 18:297-329

Corrado V, Ballarini I, Corgnati SP (2014) TABULA: building typology brochure-Italy. Fascicolo sulla Tipologia Edilizia Italiana, Nuova Edizione

Cosenza E, Manfredi G, Polese M, Verderame GM (2005) A multi-level approach to the capacity assessment of existing RC buildings. J Earthq Eng 9(1):1-22

Curioni G (1868) L'arte del fabbricare, Augusto Federico Negro Editore (in Italian)

D’Ayala D, Meslem A, Vamvatsikos D, Porter K, Rossetto T, Silva V (2014) Guidelines for analytical vulnerability assessment of low/mid-rise buildings. Vulnerability Global Component Project

da Porto F, Munari M, Prota A, Modena C (2013) Analysis and repair of clustered buildings: case study of a block in the historic city centre of L'Aquila (Central Italy). Constr Build Mater 38:1221-1237

Deb K, Pratap A, Agarwal S, Meyarivan T (2002) A fast and elitist multiobjective genetic algorithm: NSGA-II. IEEE Trans Evol Comput 6(2):182-197

Del Gaudio C, Ricci P, Verderame GM (2018) A class-oriented mechanical approach for seismic damage assessment of RC buildings subjected to the 2009 L'Aquila earthquake. Bull Earthq Eng 16(10):4581-4605

Di Pasquale G, Goretti A (2001) Functional and economic vulnerability of residential buildings affected by recent Italian earthquakes. In: Proceedings of the ' $X$ Convegno Nazionale di Ingegneria Sismica' ( $X$ ANIDIS), Potenza-Matera, Italy, September 9-13 (in Italian)

Di Sivo M (1981) Normativa e tipologia dell'abitazione popolare, l'origine e lo sviluppo nelle leggi della casa dal 1902 al 1980, Alinea Editrice (in Italian)

Dolce M, Goretti A (2015) Building damage assessment after the 2009 Abruzzo earthquake. Bull Earthq Eng 13(8):2241-2264

Dolce M, Speranza E, Giordano F, Borzi B, Bocchi F, Conte C, Di Meo A, Faravelli M, Pascale V (2019) Observed damage database of past Italian earthquakes: the Da.D.O. WebGIS. Bollettino di Geofisica Teorica ed Applicata 60(2):141-164

Donà M, Bizzaro L, Carturan F, da Porto F (2019) Effects of business recovery strategies on seismic risk and cost-effectiveness of structural retrofitting for business enterprises. Earthq Spectra 35(4):1795-1819

Donghi D (1905) Manuale dell'architetto, Utet (in Italian)

Eucentre (2018) I.R.MA. (Italian Risk Maps), Manuale di navigazione utente (in Italian)

Fabris M, Achilli V, Campostrini GP, Modena C (2013) L'aerofotogrammetria digitale per la stima delle caratteristiche strutturali degli edifici. In: Proceedings of the 'XV Convegno Nazionale di Ingegneria Sismica' (XV ANIDIS), Padova, Italy, June 30-July 4 (in Italian)

Ferrini M, Melozzi A, Pagliazzi A, Scarparolo S (2003) Rilevamento della vulnerabilità sismica degli edifici in muratura. Manuale per la compilazione della Scheda GNDT/CNR di II livello. Regione Toscana

Grünthal G (1998) European Macroseismic Scale. Chaiers du Centre Européen de Géodynamique et de Séismologie, vol. 15 Luxembourg

Guenzi C (a cura di) (1981) L'arte di edificare. Manuali in Italia 1750-1950, BE - MA editrice (in Italian)

Italian Civil Protection Department of the Presidency of the Council of Ministers - DPC (2018) National risk assessment—overview of the potential major disasters in Italy: seismic, volcanic, tsunami, hydrogeological/hydraulic and extreme weather, droughts and forest fire risks, pp 1-137

Italian, Government, Law no. 1684 of 1962/11/25 (GU no. 326 of 1962/12/22), Provvedimenti per l'edilizia, con particolari prescrizioni per le zone sismiche (in Italian)

Italian, Government, Law no. 205 of 2017/12/27, “2018 Budget Law” (in Italian) 
Italian, Government, Law no. 232 of 2016/12/11, "2017 Budget Law” (in Italian)

Italian Ministry of Infrastructures, Circolare no. 617 of 2009/02/02 (GU 2009/02/26, Suppl. Ordinario no.27), Istruzioni per l'applicazione delle 'Nuove norme tecniche per le costruzioni' di cui al decreto ministeriale 14 gennaio 2008 (in Italian)

Italian Ministry of Infrastructures, DM 1986/01/24 (GU no. 108 of 1986/05/12), Norme Tecniche relative alle costruzioni antisismiche (in Italian)

Italian Ministry of Infrastructures, DM 1987/11/20 (GU no. 285 of 1987/12/05), Norme Tecniche per la progettazione, esecuzione e collaudo degli edifici in Muratura e per il loro consolidamento (in Italian)

Italian Ministry of Infrastructures, DM 1996/01/16 (GU no. 29 of 1996/02/05), Norme tecniche relative ai criteri generali di verifica di sicurezza delle costruzioni e dei carichi e sovraccarichi (in Italian)

Italian Ministry of Infrastructures, DM no. 58 of 2017/02/28 (and subsequent DM no. 65 of 2017/03/07) "Linee Guida per la classificazione del rischio sismico delle costruzioni e disposizioni attuative del Sismabonus" (in Italian)

Italian National Institute of Statistics, ISTAT (2001) Website and data warehouse.https://www.istat.it/it/censimenti-permanenti/censimenti-precedenti/popolazione-e abitazioni/popolazione-2001

Italian Royal Decree RD no. 193 of 1909/04/18 (GU no. 95 of 1909/04/22), Norme tecniche ed igieniche obbligatorie per le riparazioni, ricostruzioni e nuove costruzioni degli edifici pubblici e privati nei Comuni colpiti dal Terremoto del 28 dicembre 1908 o da altri precedenti (in Italian)

Italian Royal Decree RDno (2089) of 1924/10/23 (GU no.303 of 1924/12/30), Norme tecniche ed igieniche per le riparazioni, ricostruzioni e nuove costruzioni degli edifici pubblici e privati nei Comuni o frazioni di comune dichiarati zone sismiche (in Italian)

Italian Royal Decree RD no. 640 of 1935/03/25 (GU no. 120 of 1935/05/22), Nuovo testo delle norme tecniche di edilizia con speciali prescrizioni per le località colpite dai terremoti (in Italian)

Kappos AJ, Panagopoulos G, Panagiotopoulos C, Penelis G (2006) A hybrid method for the vulnerability assessment of RC and URM buildings. Bull Earthq Eng 4:391

Lagomarsino S, Cattari S (2014) Fragility functions of masonry buildings. In: Pitilakis K, Crowley H, Kaynia AM (eds) Chap 5 in SYNER-G: typology definition and fragility functions for physical elements at seismic risk. Springer, Berlin, pp 111-156

Lagomarsino S, Giovinazzi S (2006) Macroseismic and mechanical models for the vulnerability assessment of current buildings. Bull Earthq Eng 4(4):415-443

Lagomarsino S, Cattari S, Ottonelli D (2015) Derivazione di curve di fragilità empiriche per classi tipologiche rappresentative del costruito Aquilano sulla base dei dati del danno dell'evento sismico del 2009. Research Project DPC-ReLUIS, PR1 (Strutture in muratura), WP6 (Vulnerabilità delle costruzioni in muratura a scala territoriale)—Task 6.3 (in Italian)

Margottini C, Molin D, Serva L (1992) Intensity versus ground motion: a new approach using Italian data. Eng Geol 33(1):45-58

Masi A, Chiauzzi L, Santarsiero G, Manfredi V, Biondi S, Spacone E, Del Gaudio C, Ricci P, Manfredi G, Verderame GM (2019) Seismic response of RC buildings during the Mw 6.0 August 24, 2016 Central Italy earthquake: the Amatrice case study. Bull Earthq Eng 17:5631-5654

Mazzocchi M, Montini A (2001) Earthquake effects on tourism in central Italy. Ann Tour Res 28(4):1031-1046

Modena C, Casarin F, Da Porto F, Munari M (2010) L'Aquila 6th April 2009 earthquake: emergency and post-emergency activities on cultural heritage buildings. In: Garevski M, Ansal A (eds) Earthquake engineering in Europe. Springer, Dordrecht, pp 495-521

Moretti B (1946) Ville. 68 Esempi di ville e case di campagna, Hoepli (in Italian)

Moretti B (1947) Case d'abitazione in Italia, Hoepli (in Italian)

Munari M (2009) Sviluppo di procedure per valutazioni sistematiche di vulnerabilità sismica di edifici esistenti in muratura, Tesi di Dottorato, Università degli Studi di Padova, Scuola di Dottorato in "Studio e Conservazione dei Beni Archeologici e Architettonici” (XXII) (in Italian)

National Institute of Geophysics and Volcanology (INGV): http://www.ingv.it/it/

Ormea GB (1951) La teoria e la pratica delle costruzioni, Hoepli (in Italian)

Penna A, Morandi P, Rota M, Manzini CF, da Porto F, Magenes G (2014) Performance of masonry buildings during the Emilia 2012 earthquake. Bull Earthq Eng 12(5):2255-2273

Rossetto T, Ioannou I, Grant DN (2013) Existing empirical fragility and vulnerability functions: compendium and guide for selection. GEM Technical Report 2013-X, GEM Foundation, Pavia, Italy

Rosti A, Rota M, Penna A (2018) Damage classification and derivation of damage probability matrices from L'Aquila (2009) post-earthquake survey data. Bull Earthq Eng 16(9):3687-3720

Rota M, Penna A, Strobbia C (2008) Processing Italian damage data to derive typological fragility curves. Soil Dyn Earthq Eng 28(10):933-947 
Sorrentino L, Cattari S, da Porto F, Magenes G, Penna A (2019) Seismic behavior of ordinary masonry buildings during the 2016 Central Italy Earthquakes. Bull Earthq Eng 17(10):5583-5607

Swiss Reinsurance Company (2019) L'Aquila, 10 anni dopo. Sigma No. 2/2019. Swiss Re Institute, Zurich (in Italian)

Taffarel S (2016) Metodi speditivi per la valutazione della vulnerabilità sismica del costruito storico: approccio all'incertezza nelle forme di aggregazione complessa a diversa scala. Tesi di Dottorato, Università degli Studi di Padova, Corso di Dottorato di Ricerca in "Storia, Critica e Conservazione dei Beni Culturali" (XXIX) (in Italian)

Taffarel S, da Porto F, Valluzzi MR, Modena C (2018) Comparing expeditious procedures for the seismic vulnerability assessment on the European territorial context: reliability, feasibility, cost, and time consumption. Int J Archit Herit 12:7-8

Tecchio G, Donà M, da Porto F (2016) Seismic fragility curves of as-built single-span masonry arch bridges. Bull Earthq Eng 14(11):3099-3124

United Nations International Strategy for Disaster Reduction (2015) Sendai framework for disaster risk reduction 2015-2030. https://www.unisdr.org/files/43291_sendaiframeworkfordrren.pdf

Valluzzi MR (2009) User Manual of Vulnus_4.0, original program by Bernardini Gori A, Modena R C, Vb version edited by Valluzzi MR, with contributions by Benincà G, Barbetta E, Munari M (in Italian)

Valluzzi MR, Munari M, Modena C, Binda L, Cardani G, Saisi A (2007) Multilevel approach to the vulnerability analysis of historic buildings in seismic areas part 2: analytical interpretation of mechanisms for vulnerability analysis and structural improvement. Restor Build Monum 13(6):427-441

Vona M, Cascini G, Mastroberti M, Murgante B, Nolè G (2017) Characterization of URM buildings and evaluation of damages in a historical center for the seismic risk mitigation and emergency management. Int J Disas Risk Reduct 24:251-263

Publisher's Note Springer Nature remains neutral with regard to jurisdictional claims in published maps and institutional affiliations.

\section{Affiliations}

\section{Marco Donà ${ }^{1,2} \oplus \cdot$ Pietro Carpanese $^{2} \cdot$ Veronica Follador $^{2} \cdot$ Luca Sbrogió $^{3}$. Francesca da Porto ${ }^{2}$}

Pietro Carpanese

pietro.carpanese@phd.unipd.it

Veronica Follador

veronica.follador@unipd.it

Luca Sbrogiò

luca.sbrogio@phd.unipd.it

Francesca da Porto

francesca.daporto@unipd.it

1 Earthquake Engineering Research and Test Center, Guangzhou University, Guang Yuan Zhong Rd. 248, Guangzhou 510405, China

2 Department of Geosciences, University of Padova, Via G. Gradenigo 6, 35131 Padua, Italy

3 Department of Cultural Heritage, University of Padova, Piazza Capitaniato 7, 35139 Padua, Italy 